\title{
Antigen Specificity Enhances Disease Control by Tregs in Vitiligo
}

\section{OPEN ACCESS}

Edited by:

Michele Marie Kosiewicz, University of Louisville, United States

Reviewed by: Rasheedunnisa Begum, Maharaja Sayajirao University of Baroda, India Jillian M. Richmond, University of Massachusetts Medical School, United States

*Correspondence:

Zhussipbek Mukhatayev zhussipbek.mukhatayev@nu.edu.kz 1. Caroline Le Poole caroline.lepoole@northwestern.edu

Specialty section: This article was submitted to Autoimmune and Autoinflammatory Disorders, a section of the journal

Frontiers in Immunology

Received: 08 July 2020 Accepted: 27 October 2020 Published: 01 December 2020

Citation:

Mukhatayev Z, Dellacecca ER, Cosgrove $C$, Shivde $R$, Jaishankar D, Pontarolo-Maag K, Eby JM, Henning SW

Ostapchuk YO, Cedercreutz $K$ Issanov A, Mehrotra S, Overbeck A, Junghans RP, Leventhal JR

and Le Poole IC (2020) Antigen

Specificity Enhances Disease

Control by Tregs in Vitiligo.

Front. Immunol. 11:581433. doi: 10.3389/fimmu.2020.581433
Zhussipbek Mukhatayev ${ }^{1,2,3,4 *}$,Emilia R. Dellacecca ${ }^{1,2}$, Cormac Cosgrove ${ }^{1,2}$, Rohan Shivde ${ }^{1,2}$, Dinesh Jaishankar ${ }^{1,2}$, Katherine Pontarolo-Maag ${ }^{5}$, Jonathan M. Eby ${ }^{5}$, Steven W. Henning ${ }^{5}$, Yekaterina O. Ostapchuk ${ }^{4}$, Kettil Cedercreutz ${ }^{1}$, Alpamys Issanov ${ }^{6}$, Shikhar Mehrotra ${ }^{7}$, Andreas Overbeck ${ }^{8}$, Richard P. Junghans ${ }^{9}$, Joseph R. Leventhal ${ }^{10}$ and I. Caroline Le Poole ${ }^{1,2 *}$

${ }^{1}$ Department of Dermatology, Northwestern University, Chicago, IL, United States, ${ }^{2}$ Robert H. Lurie Comprehensive Cancer Center, Northwestern University, Chicago, IL, United States, ${ }^{3}$ Faculty of Biology and Biotechnology, Al-Farabi Kazakh National University, Almaty, Kazakhstan, ${ }^{4}$ Laboratory of Molecular immunology and Immunobiotechnology, M.A. Aitkhozhin's Institute of Molecular Biology and Biochemistry, Almaty, Kazakhstan, ${ }^{5}$ Oncology Research Institute, Loyola University, Maywood, IL, United States, ${ }^{6}$ Department of Medicine, School of Medicine, Nazarbayev University, Nur-Sultan, Kazakhstan, 7 Department of Surgery, Medical University of South Carolina, Charleston, SC, United States, ${ }^{8}$ Department for Surgery of Pigment Disorders, Lumiderm, Madrid, Spain, ${ }^{9}$ Department of Hematology/Oncology, Boston University, Boston MA, United States, ${ }^{10}$ Comprehensive Transplant Center, Northwestern Memorial Hospital, Chicago, IL, United States

Vitiligo is an autoimmune skin disease characterized by melanocyte destruction. Regulatory T cells (Tregs) are greatly reduced in vitiligo skin, and replenishing peripheral skin Tregs can provide protection against depigmentation. Ganglioside D3 (GD3) is overexpressed by perilesional epidermal cells, including melanocytes, which prompted us to generate GD3-reactive chimeric antigen receptor (CAR) Tregs to treat vitiligo. Mice received either untransduced Tregs or GD3-specific Tregs to test the hypothesis that antigen specificity contributes to reduced autoimmune reactivity in vitro and in vivo. CAR Tregs displayed increased IL-10 secretion in response to antigen, provided superior control of cytotoxicity towards melanocytes, and supported a significant delay in depigmentation compared to untransduced Tregs and vehicle control recipients in a TCR transgenic mouse model of spontaneous vitiligo. The latter findings were associated with a greater abundance of Tregs and melanocytes in treated mice versus both control groups. Our data support the concept that antigen-specific Tregs can be prepared, used, and stored for long-term control of progressive depigmentation.

Keywords: vitiligo, regulatory $\mathbf{T}$ cells, chimeric antigen receptor $\mathbf{T}$ cells, ganglioside D3, antigen-specific Treg, autoimmune diseases

\section{INTRODUCTION}

Vitiligo is an autoimmune disease wherein melanocytes are progressively destroyed, resulting in pale, white patches of skin $(1,2)$. The prevalence of vitiligo is $0.5-1 \%$, and this disorder is associated with low self-esteem, psychological stress, and social stigma (3-5). Therapies currently available for vitiligo have limited efficacy, and a real need for new treatment strategies exists (6). Several factors contribute to the pathogenesis of vitiligo. Oxidative stress in melanocytes can trigger the release of inducible heat shock protein 70 (HSP70i) (7). HSP70i can directly activate innate immune cells and 
chaperone melanocyte antigens for subsequent introduction to antigen presenting cells (APCs) $(8,9)$. In turn, these innate immune cells and APCs recruit auto-reactive $\mathrm{T}$ cells to mediate specific destruction of melanocytes in vitiligo (10). The loss of tolerance to self-antigens also involves reduced cutaneous regulatory $\mathrm{T}$ cell (Treg) activity $(11,12)$. Tregs are subsets of $\mathrm{T}$ cells responsible for peripheral tolerance via suppression of immune cells, including self-reactive, cytotoxic $\mathrm{T}$ cells, to maintain immune homeostasis (13). Paucity of and defects in Tregs have been reported in several autoimmune disorders (1416). A local deficiency in Tregs was found in vitiligo skin within lesional, non-lesional, and perilesional sections, thereby suggesting a reduced ability of vitiligo patients to maintain peripheral immune homeostasis $(17,18)$. Others have reported that Tregs may be circulating in reduced number or exhibit reduced activity $(16,19)$. Limited Treg activity in vitiligo skin allows autoreactive, cytotoxic $\mathrm{T}$ cells to expand and eliminate melanocytes from the skin, facilitating progressive depigmentation (12).

To date, adoptive transfer of polyclonal Tregs has been used in clinical trials for several conditions wherein autologous cells were amplified in vitro and re-administered to patients, with limited success (20). In a mouse model of vitiligo, this approach was beneficial, by short term-maintenance of a favorable Treg to effector $\mathrm{T}$ cell ratio in this setting (21). Application of polyclonal Tregs can however impart systemic immunosuppression, via inadvertent dampening of responses to infection or malignancies, posing an important clinical consideration (22). Furthermore, generating sufficient numbers of polyclonal Tregs for clinical use can be challenging. Generic immunosuppression can present an issue that might be overcome by including antigen specificity to adoptively transferred cells. In transplant biology, antigen-specific Tregs are showing promise to provide local immunosuppression at the site of disease progression by targeting human leukocyte antigen (HLA) discrepancies between donor and recipient (23). Antigenspecific Tregs might offer significant advantages for the treatment of vitiligo as well.

Antigen-specific Tregs can be generated by introducing T-cell receptors (TCRs), but applications of these TCR-Tregs are limited by major histocompatibility complex (MHC)restriction, not allowing all patients to benefit (24). Our study instead makes use of antigen-specific Tregs transduced to express a chimeric antigen receptor (CAR), which overcomes MHCdependency. In CAR-T cell therapy, optimizing and selecting the correct CAR affinity and intracellular signaling domains is particularly important for the resulting therapeutic activity and cellular persistence of the Tregs. Since CARs are constructed using antibody variable regions, they hold higher affinity to their cognate antigen compared to TCRs (25). Also important is the identification of a cell surface antigen that is relatively abundant in the affected tissue under study and can be targeted by CAR Tregs. The concept is then that the selected surface antigen can serve as a target for antigen-specific CAR Tregs to selectively and locally suppress auto-reactive T cells in vitiligo (26). These results can be compared to those achieved using a tyrosinase-reactive TCR. The latter approach, tested in an immunodeficient melanoma model was the first to demonstrate activity for adoptively transferred, antigen-specific Tregs (27). Both the tyrosinase and HLA-A2 encoding-genes are associated with vitiligo disease development, rendering relevance to tyrosinasereactive $\mathrm{T}$ cells, as well as to the associated $\mathrm{HLA}^{*} \mathrm{~A}^{\star} 0201$ restriction (28). The same combination of TCR and MHC transgenes was used to generate the h3TA2 mouse model of vitiligo, used here to host our CAR transgenic Tregs (29). These mice develop rapid, continuous depigmentation with most differentiated pigment cell lost from the skin by 5 weeks of age (30). This aggressive model of disease sets a high bar for therapeutics to be effective and can provide a first estimate of efficacy for new therapeutics (30). The ganglioside D3 (GD3) antigen, meanwhile, holds relevance as GD3 expression is found in stressed melanocytes, and likely more prominently so in perilesional skin of vitiligo patients (31). This GD3 antigen is currently targeted for immunotherapy of melanoma as for its expression on membrane and accessibility to antibodies $(32,33)$. Besides, GD3 contributes to melanogenesis, cell growth, and cell dendricity $(34,35)$. To test the therapeutic potential of antigenspecific Tregs for the treatment of vitiligo, we isolated naïve $\mathrm{T}$ cells and polarized them towards Tregs before introducing a GD3-responsive CAR-encoding construct. Resulting cells were tested for cytokine secretion to relevant targets in vitro, and resulting cytotoxicity was measured. Finally, in a mouse model of progressive vitiligo, we have introduced the resulting CARtransgenic Tregs to test their treatment potential in vivo. This includes evaluating depigmentation, and the persistence of Tregs and melanocytes in the skin. Adoptive transfer of antigenspecific Tregs may offer an exciting opportunity to halt depigmentation and to complement up-and-coming therapeutics such as modified inducible HSP70 to tolerize dendritic cells (DCs) and Janus kinase (JAK) inhibitors to mitigate $\mathrm{T}$ cell activation $(36,37)$.

\section{MATERIALS AND METHODS}

\section{Study Design}

The purpose of this study was to investigate the efficacy of GD3 CAR Tregs to halt progressing depigmentation in a mouse model of human vitiligo. We polarized and amplified Tregs in vitro before generating antigen-specific Tregs using a CAR construct to generate GD3 CAR Tregs with high transduction efficiencies. To define in vitro effects, we co-cultured human HLA-A2 ${ }^{+}$ melanocytes along with tyrosinase reactive effector $\mathrm{T}$ cells in the presence of untransduced Tregs and GD3 CAR Tregs. For in vivo efficacy, we adoptively transferred untransduced Tregs, GD3 CAR Tregs, and HBSS vehicle into a humanized mouse model prone to develop vitiligo, subjecting the animals to depigmentation analysis, while evaluating the local and distant effects of CAR Tregs by immunohistology and multiplex cytokine analysis. Human skin from vitiligo patients were stained for GD3 expression on lesional, perilesional, and nonlesional skin. 
Sample sizes for in vivo experiments were determined based on statistical power calculations from previous studies and past experience with the h3TA2 mouse model of vitiligo. For in vivo studies, mice were randomly assigned to groups with regard to sex, and investigators were blinded to the experimental conditions and to the further analysis. All the experimental samples and animals were included in the analysis, with no exclusion of outliers. Sample sizes, replicates, and statistical methods are indicated in the results and in the figure legends.

\section{Tissue Procurement, Cell Culture, and Reagents}

Human perilesional skin tissue was obtained with informed consent from vitiligo patients attending the Dermatology clinic at Loyola University Medical Center in Maywood, IL (Supplementary Table 1). Studies were approved by the Institutional Review Board in adherence to principles described in the Declaration of Helsinki. Naïve mouse $\mathrm{CD}^{+} \mathrm{T}$ cells and $\mathrm{CD}^{+}{ }^{+}$FoxP $^{+}$Tregs were cultured in RPMI media supplemented with 10\% FBS, $1 \mathrm{X}$ non-essential amino acids (Corning), $50 \mathrm{U} / \mathrm{ml}$ Penicillin-Streptomycin (Thermo Fisher Scientific), $1 \mathrm{mM}$ Sodium Pyruvate (Gibco Life Technologies), $10 \mathrm{mM}$ HEPES (Gibco Life Technologies), and $50 \mu \mathrm{M} \beta$-Mercaptoethanol (Sigma Aldrich). Human melanocytes were cultured in Human Melanocyte Growth Supplement-2 (Thermo Fisher Scientific) added to Medium 254 (Thermo Fisher Scientific) with $10 \mathrm{mM}$ L-Glutamine (Thermo Fisher Scientific) and 1X antibioticantimycotic (Thermo Fisher Scientific). Rabbit anti-GD3 CAR sera and stable GD3 CAR virus producing cells were generated as described (38). Stable GD3 CAR virus producing cells (VPCs) were maintained in the above described $\mathrm{T}$ cell medium for virus production.

\section{Isolation of Naïve CD4+ T Cells and Polarization to CD4+FoxP3+ Tregs In Vitro}

Naïve mouse $\mathrm{CD}^{+} \mathrm{T}$ cells were isolated from spleens of 8-10 week-old B6.Cg-Foxp $3^{\text {tm } 2 \text { Tch }} / \mathrm{J}$ ("FoxP3 eGFP") reporter mice (Jackson Laboratories) using EasySep Mouse naive CD4+ T cell isolation kit (StemCell Technologies) following the manufacturer's protocol. These mice co-express enhanced green fluorescent protein (eGFP), which is restricted to the $\mathrm{T}$ cell lineage, primarily to the $\mathrm{CD} 4^{+} \mathrm{T}$ cell population. Naïve $\mathrm{CD} 4^{+}$ $\mathrm{T}$ cells were polarized to $\mathrm{CD} 4^{+} \mathrm{FoxP}^{+}$using $30 \mathrm{ng} / \mathrm{ml}$ human transforming growth factor beta (TGF- $\beta$ ) (eBioscience) in the presence of Dynabeads $^{\mathrm{TM}}$ Mouse T-Activator CD3/CD28 (Thermo Fisher Scientific) with a 1:1 bead to cell ratio and 300 international units $/ \mathrm{ml}(\mathrm{IU} / \mathrm{ml})$ of recombinant human interleukin 2 (rhIL-2) (NIH, Bethesda, MD) for 5 days. Human TGF- $\beta$ was used to polarize murine Tregs as mouse and human TGF- $\beta$ share $99 \%$ sequence homology with high cross-species activity $(39,40)$. Human IL-2 was used as human IL-2 efficiently stimulates mouse IL-2 receptor, whereas mouse IL-2 does not elicit efficient binding to human IL-2 receptors $(41,42)$.

\section{Generation of GD3 CAR Transduced Mouse Tregs}

Twenty-four well non-tissue culture plates were coated with $10 \mu \mathrm{g} / \mathrm{ml}$ retronectin (Takara Bio USA Inc.). The MFG retroviral vector-based second generation CAR construct (sFvCD28/TCR $\zeta$ ) reactive to GD3 was generated as described (43). Conditioned medium supernatant from Phoenix E retroviral producer cells (43) consisting of GD3 CAR-encoding virus ( $80 \%$ confluent) $(43,44)$ was transferred to retronectin coated plates and centrifuged at 2,000xg. Supernatant was carefully removed and activated $\mathrm{CD}^{+}{ }^{+} \mathrm{FoxP}^{+}$Tregs were transferred to the retronectin coated plates with additional viral supernatant, $5 \mu \mathrm{g} / \mathrm{ml}$ protamine sulfate (Sigma Aldrich) and $300 \mathrm{IU} / \mathrm{mL}$ rhIL2. Plates were centrifuged at $1,000 \mathrm{xg}$, before an incubation with complete $\mathrm{T}$ cell culture medium and mouse T-Activator CD3/CD28 beads and rhIL-2 as above. The transduction was then repeated to increase the transduction efficiency. Transduced Tregs were reactivated with CD3/CD28 beads, $30 \mathrm{ng} / \mathrm{ml}$ human TGF- $\beta$ and rhIL- 2 for 2 days before flow analysis.

\section{Flow Cytometry}

Prior to surface staining, cells were incubated with mouse Fc Block (BioLegend) and LIVE/DEAD Fixable Near Infrared Dead Cell dye (Thermo Fisher Scientific) according to the manufacturer's instructions. Surface staining of directly labeled antibodies included BUV395-labeled anti-mouse CD3 clone 145-2C11 (BD Biosciences), and BV421-labeled anti-mouse CD4 clone GK1.5 (BioLegend). The eGFP marker expressed under the FoxP3 promoter in Treg reporter mice, as well as BB700- labeled rat anti-mouse CD25 clone PC61 (BD Biosciences) were used to identify Tregs. Unlabeled anti-GD3 CAR rabbit sera detected by anti-rabbit allophycocyanin (APC) (Invitrogen) antibodies were used to evaluate CAR expression by transgenic Tregs. Stained cells were analyzed using a BD FACSymphony flow cytometer and FlowJo v10.3.0 software (FlowJo LLC, OR, USA).

\section{In Vitro Co-Culture Experiments}

HLA-A2 ${ }^{+}$melanocytes were identified by immunofluorescent staining using FITC-labeled BB7.2 to human HLA-A2 prior to in vitro co-culture experiments. Human $\mathrm{HLA}-\mathrm{A} 2^{+}$neonatal foreskin melanocytes (Mf0887, P6) and HLA-A2- abdominoplastic skin melanocytes (Ms18001, P6) were plated with tyrosinase reactive h3T effector T cells (Teffs) (29) and either untransduced or GD3 CAR-transduced suppressor Tregs at 10:1:1 effector to target to suppressor ratio for $36 \mathrm{~h}$. Teff : Tregs ratio was used to mimic the natural occurrence of the T cell subsets as Tregs comprise 5-10\% of the total $\mathrm{T}$ cell population Co-cultures were seeded in triplicates and incubated using IncuCyte ${ }^{\circledR}$ Caspase-3/7 Red Apoptosis Assay Reagent (Sartorius). Images were taken every $3 \mathrm{~h}$, in triplicate, using the IncuCyte live-cell analysis system (Sartorius). Supernatants were saved for mouse IFN- $\gamma$ (R\&D systems, Minnesota, MN) and IL-10 ELISA assay (Mabtech AB, Stockholm, Sweden) performed according to the manufacturer's protocols. Cytotoxicity was examined by quantifying live cells 
relative to control wells using Adobe Photoshop (Adobe Systems, San Jose, CA).

\section{Adoptive Treg Transfer}

Transgenic h3TA2 recipient mice with T cells expressing a TCR reactive to the human tyrosinase 368-376 (YMDTMSQV) epitope (21) were maintained under protocols approved by Northwestern University's Institutional Animal Care and Use Committee (IACUC) following guidelines for the care and use of laboratory animals as outlined by the US National Research Council. Mice were retro-orbitally administered $2 \times 10^{5}$ untransduced Tregs/per animal $\left(\mathrm{n}=11 ; 60^{\star}, 5 \%\right)$ or $2 \times 10^{5} \mathrm{GD} 3$ CAR Tregs/per animal $(\mathrm{n}=11 ; 6 \hat{0}, 5$ \%), or treated with vehicle (HBSS) alone ( $\mathrm{n}=12 ; 6 \hat{0}, 60$ ) four times, every two weeks, starting at 5 weeks of age. The number of adoptively transferred Tregs was identified to enable a comparison to our earlier studies (21), where the $2 \times 10^{5}$ polyclonal Tregs controlled depigmentation in in the human Tyrosinase TCR TransgenicHLA-A2 (h3TA2) mouse model between 3-9 weeks old mice. All groups received low dose of recombinant human IL-2 (3,000 IU) 3 times a week throughout the entire experiment to promote in vivo stimulation of adoptively transferred Tregs $(45,46)$. Animals were maintained for 15 weeks and humanely euthanized. Experiments were initiated at 6 different time points, including mice from different litters. Naïve $\mathrm{T}$ cells were polarized and transduced to generate CAR Treg for up to 4 mice/ group at a time. Depigmentation was monitored for each experiment over time, with results pooled to further substantiate the results. Skin biopsies, spleen, brain, ileum, lymph nodes were maintained in optimal cutting temperature (OCT), and serum was stored for cytokine analysis.

\section{Depigmentation Analysis}

From 5 weeks to 15 weeks of age, mice were scanned weekly on a flatbed scanner (Hewlett-Packard, Palo Alto, CA) under isoflurane anesthesia. Using Adobe Photoshop software (Adobe Systems) ventral and dorsal luminosity was measured to calculate depigmentation, as previously described (47). Depigmentation was graphed over time, and statistical significance was determined by the time-adjusted area under the curve (AUC). Representing change in depigmentation from treatment initiation was calculated using the trapezoidal rule. No imputation was done for missing data, and the AUC for each mouse was divided by the total number of weeks of available data minus 1. The Wilcoxon Rank Sum (WRS) test was used to compare the time-adjusted AUC among groups.

\section{Immunohistology}

Mouse and human skin samples were frozen using OCT Compound (Sakura Finetek) on dry ice. Eight $\mu \mathrm{m}$ cryosections were cut (Leica). For FoxP3/CD3 staining, sections were paraformaldehyde-fixed and permeabilized using True-Nuclear Transcription factor buffer set (BioLegend). Sections were treated with SuperBlock (ScyTek Laboratories, Logan, UT). PE-labeled antibody $145-2 \mathrm{C} 11$ to mouse CD3€ (Biolegend) and Alexa Fluor 488-labeled antibody MF-14 to mouse FoxP3 (BioLegend) were used for double staining procedures, followed by 4',6-diamidino2-phenylindole (DAPI) (BD Biosciences) nuclear staining. For other tissue stainings, mouse and human skin sections were fixed in cold acetone. Mouse skin sections were blocked with SuperBlock and then incubated with either antibody H-90 to TRP-1 (Santa Cruz Biotechnology, Dallas, TX) followed by Alexa Fluor 555 labelled donkey anti-rabbit antibody (abcam), or PElabeled MB3.6 to GD3 (Santa Cruz Biotechnology), or PE-labeled antibody YGITR 765 to Glucocorticoid-Induced TNF Receptor (GITR) (Biolegend), or AF488-labeled antibody B56 to Ki67 (BD Biosciences), all followed by DAPI nuclear staining. Human skin sections were blocked with $10 \%$ normal human serum (Gemini Bio Products, West Sacramento, CA) and then incubated with Ta99 to TRP-1 (BioLegend) or R24 to GD3 (Abcam, Cambridge, UK). Both were detected by an HRPconjugated goat anti-mouse IgG antibody (Agilent Dako, Santa Clara, CA). These stainings were developed using AEC substrate (Abcam) and nuclei were subsequently detected by incubation in Mayer's hematoxylin (Sigma-Aldrich) and blued in Scott's tap water (Sigma-Aldrich). Slides were imaged on a Revolve microscope (Echo Laboratories). Cells were quantified using Adobe Photoshop software.

\section{Cytokine Analysis}

Included in cytokine analysis were supernatants from in vitro suppression assays (IncuCyte experiments), collected $36 \mathrm{~h}$ postco-culture, and serum samples from HBSS vehicle $(\mathrm{n}=11)$, untransduced $(n=10)$, and GD3 CAR Tregs $(n=9)$ treated mouse groups. Detection of murine Interferon gamma (IFN- $\gamma$ ), tumor necrosis factor (TNF- $\alpha$ ), IL-4, and IL-10 was performed by using a custom made $\mathrm{V}$-Plex panel for these mouse cytokines (Meso Scale Diagnostics, LLC) according to manufacturer's instructions. Data were acquired on MESO Quickplex SQ120 (Meso Scale Diagnostics, LLC) and analyzed using Prism version 8.3.0 (GraphPad Software).

\section{Statistical Analysis}

Statistical analysis was performed using GraphPad Prism 8.0 software (GraphPad) and R-software. Data are presented as bars and dot plots with mean values \pm standard deviation. The data were evaluated by one-way analysis of variance (ANOVA) analysis of variance accounting for different variances across the treatment groups, with post-hoc Tukey-Kramer comparisons. To determine statistical significance for immunosuppression in vitro, two-way ANOVAs were used with aligned rank transformation followed by multiple pairwise comparison testing using Tukey approach. For depigmentation, the time-adjusted AUC, representing change in depigmentation from treatment initiation, was calculated using the trapezoidal rule. No imputation was done for missing data, and the AUC for each mouse was divided by the total number of weeks of available data minus 1 . The WRS test was used to compare the time-adjusted AUC among groups. Statistical significance is represented as ${ }^{\star} \mathrm{p}<0.05$, ${ }^{* *} \mathrm{p}<0.01$, ${ }^{\star * *} \mathrm{p}<$ 0.001 , or ${ }^{* * * *} \mathrm{p}<0.0001$. 


\section{RESULTS}

\section{GD3 Is Expressed by Perilesional Epithelial Cells Including Melanocytes}

Overexpression of O-acetylated GD3 has been reported for actively depigmenting vitiligo skin $(31,38)$. This prompted us to evaluate GD3 expression itself in skin biopsies from perilesional biopsies taken from actively depigmenting skin. Marked expression of GD3 was observed in human vitiligo perilesional epidermis (Figure 1A), while melanocytes are absent from the border biopsy section shown (Figure 1B). Vacuolization in Figure $\mathbf{1 A}$ and $\mathbf{1 B}$ is frequently observed in vitiligo skin, and has been proposed as an indication of vitiligo by others $(48,49)$. Epidermal GD3 expression was not observed in healthy control skin (Figure 1C) whereas melanocytes are readily detectable in this tissue (Figure 1D). Similarly, GD3 expression was found in depigmenting h3TA2 mouse skin (Figure 1E).

\section{High Viral Transduction of Tregs Was Achieved With GD3-Encoded CAR Construct}

To generate therapeutic Tregs that will engage in suppressive activity where needed, we generated FoxP3 ${ }^{+} \mathrm{CD} 4^{+} \mathrm{T}$ cells and transduced them to express a GD3-reactive CAR. In a representative example, approximately $1.5 \times 10^{6}$ naïve $\mathrm{CD}^{+} \mathrm{T}$ cells were isolated from $3 \times 10^{8}$ splenocytes, maintained in presence of TGF- $\beta$, and successfully polarized and amplified to approximately $1.6 \times 10^{7}$ Tregs per donor mouse. TGF- $\beta$-polarized naïve $\mathrm{CD}^{+} \mathrm{T}$ cells were retrovirally transduced and GD3 CAR expression was evaluated by flow cytometry. The gating strategy is shown in Figure $\mathbf{2 A}$, where $86.6 \%$ of total $\mathrm{CD}^{+} \mathrm{T}$ cells were successfully transduced with the GD3 CAR construct (Figure 2B). After further expansion, $64 \pm 3.5 \%$ transduced cells were FoxP3 ${ }^{+}$ Tregs. From an initial pre-expansion and transduction pool of $4 \times 10^{6}$ FoxP $^{+}$Tregs, $2.1 \times 10^{7}$ GD3 CAR-expressing, FoxP3 ${ }^{+}$Tregs were generated. The majority of resulting CAR transduced Tregs are expected to function as immunosuppressive T cells, and exert a local, immunosuppressive function. We next measured GD3 CAR Treg function in vitro.

\section{Antigen Specificity Increases Immunosuppressive Cytokine Production}

Production of representative cytokines IFN- $\gamma$, TNF- $\alpha$, IL- 4 , and IL-10, relevant to immune activation or immunosuppression, was measured in co-cultures of GD3 CAR Tregs or untransduced Tregs with tyrosinase-reactive Teffs and their HLA-matched targets (1:10:1), measuring concentrations $42 \mathrm{~h}$ after cells were combined in culture in presence of IL-2 (Figure 3). Human melanocytes can be recognized by these Teffs (29). No significant differences in IFN- $\gamma$ production were found in combinations that do or do not contain Tregs, suggesting that the latter had little influence on the production of this cytokine at this Treg to Teff ratio (Figure 3A). Significantly more TNF- $\alpha$ (Figure 3B, p = 0.0005 ), IL-4 (Figure 3C, $\mathrm{p}=0.03$ ), and IL-10 (Figure 3D, $\mathrm{p}=$ $0.0005)$ was produced in combinations with CAR Tregs, though overall IL-4 production remained consistently low. Importantly, increased IL-10 regulatory cytokine production was observed only in presence of cytotoxic T cells and HLA-matched human
A
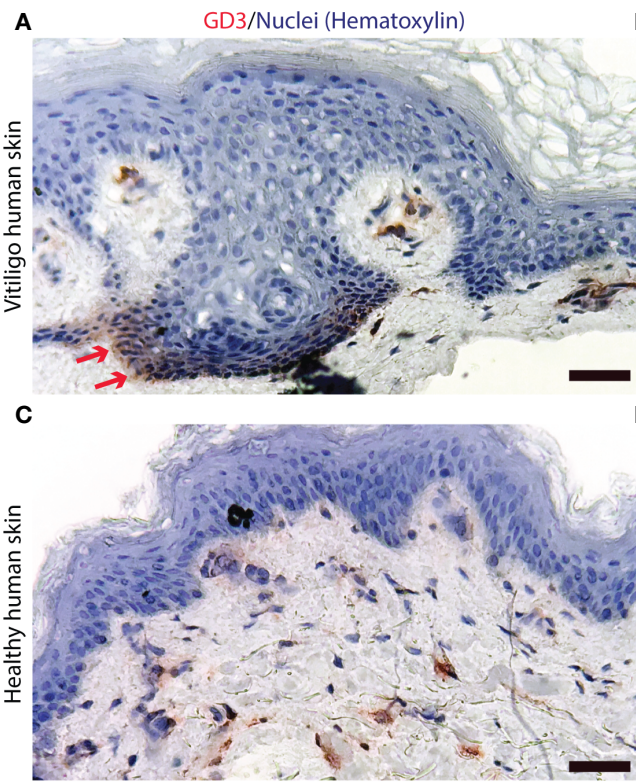

B

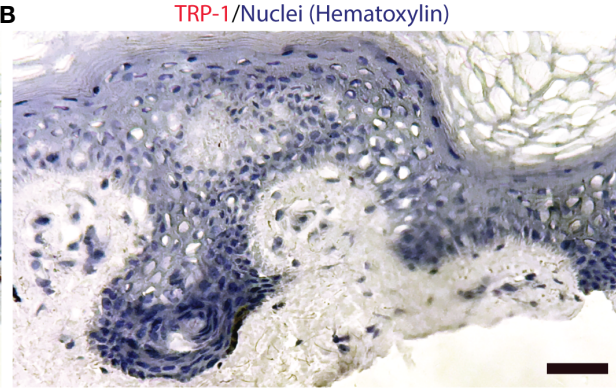

D

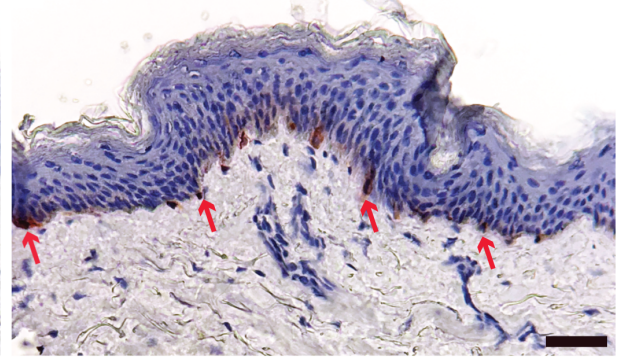

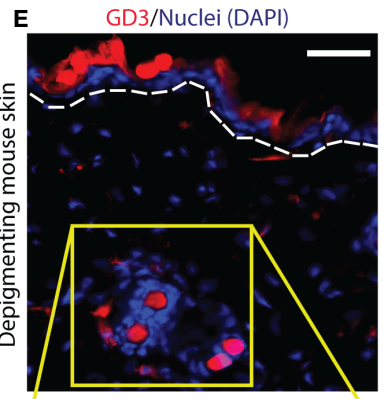

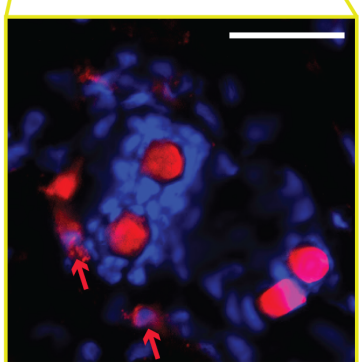

FIGURE 1 | Ganglioside D3 is expressed in depigmenting skin of human and mouse origin. (A) Expression of GD3 and (B) a lack of melanocytes, as represented by an absence of TRP-1+ staining, were found in human depigmenting epidermis from perilesional patient skin. Whereas (C) limited GD3 expression and (D) abundant TRP-1 expression are shown in healthy control skin. (E) In depigmenting mouse skin, GD3 expressing cells were observed around hair follicles and in proximity to the epidermis. Representative staining of GD3 expressing cells is shown in red with nuclei in blue, around autofluorescent mouse hairs (Scale bar $=50 \mu \mathrm{m})$. 
A

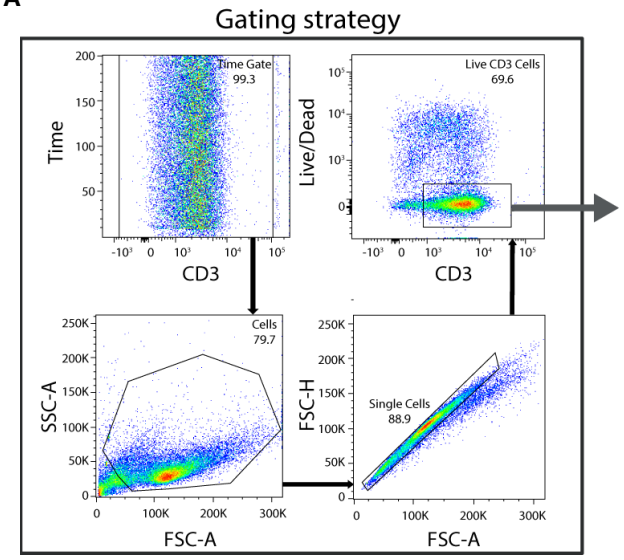

B

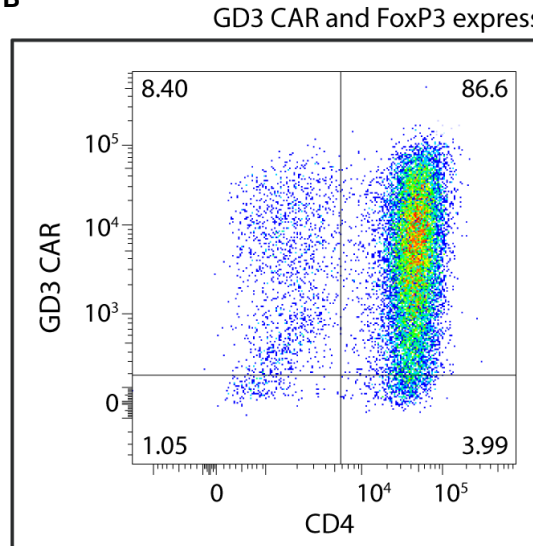

GD3 CAR and FoxP3 expression on total CD4+ T cells

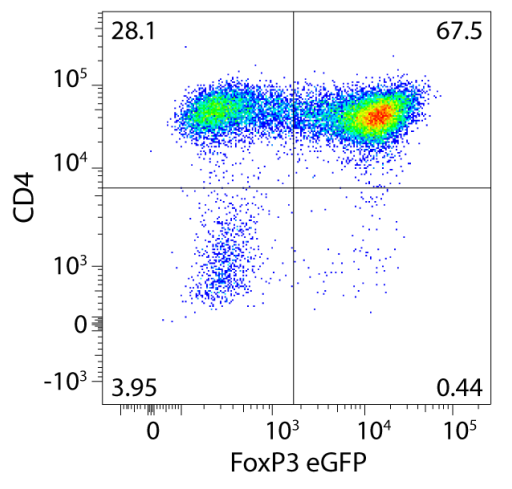

FIGURE 2 | High transduction efficiencies are observed for Tregs expressing the GD3 CAR. CD4 ${ }^{+}$FoxP3 ${ }^{+}$cells, polarized from naïve CD4 ${ }^{+}$T cells, were transduced using a GD3 CAR-encoding construct. (A) The gating strategy consists of a time gate followed by sequentially gating on lymphocytes, single cells, and live cells. (B) Eighty-six percent of total CD4 ${ }^{+} \mathrm{T}$ cells were successfully transduced to express the GD3 CAR construct and $67 \%$ of that population express FoxP3 ${ }^{+}$.
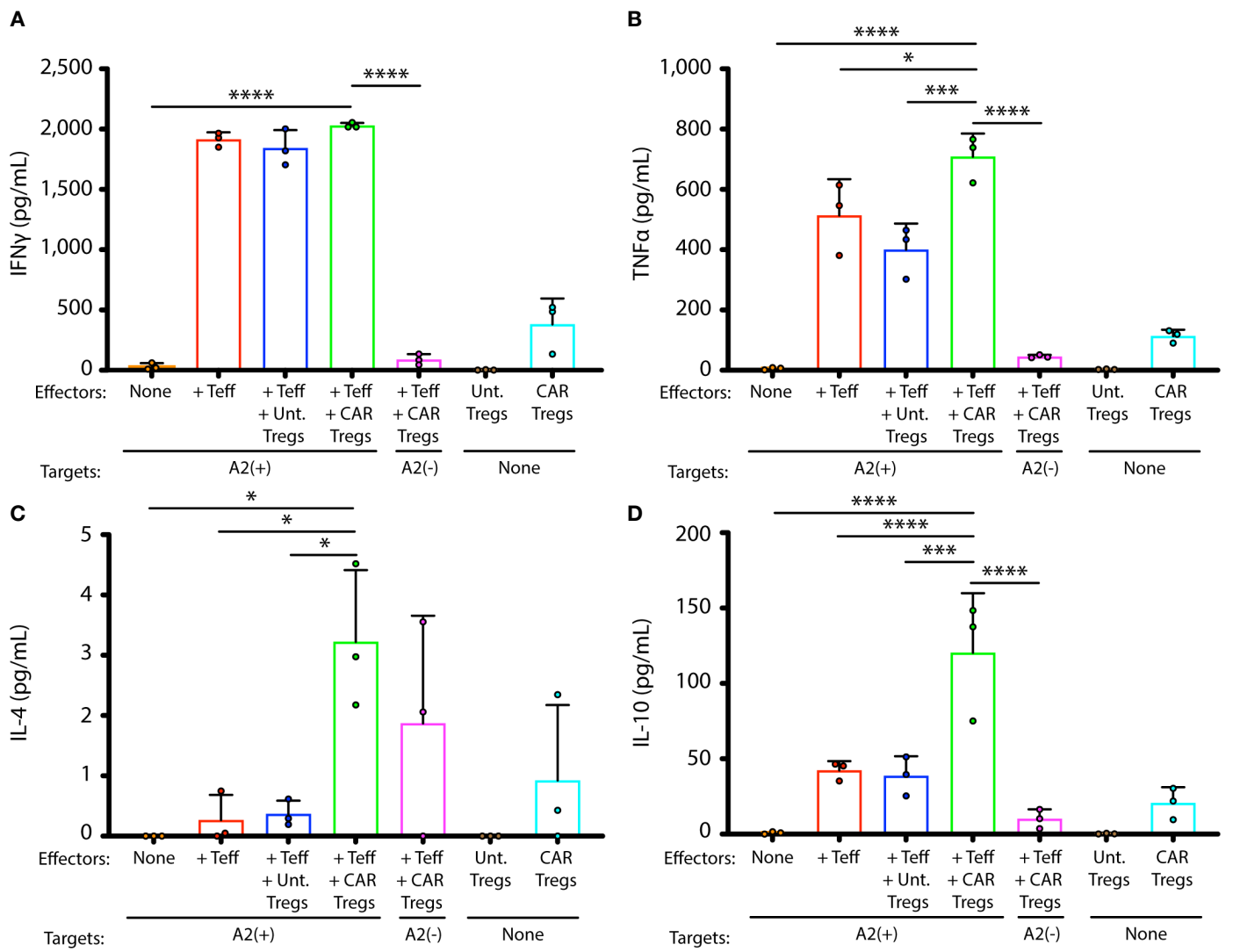

FIGURE 3 | GD3 CAR Tregs generate immunosuppressive cytokines in presence of activated T cells. Cytokines were measured in supernatants from cocultures of melanocyte targets and HLA-A2-restricted Teffs, in presence and absence of untransduced or CAR-transduced Tregs. Cytokine concentrations for each coculture, measured in triplicate cocultures, are shown for (A) IFN- $\gamma$, (B) TNF- $\alpha$, (C) IL-4, and (D) IL-10. Statistical analysis was performed by a one-way ANOVA test followed by Tukey's post-hoc test for multiple comparisons. ${ }^{\star} p<0.05 ;{ }^{* \star} p<0.01 ;{ }^{\star \star \star} p<0.001 ;{ }^{* \star \star} p<0.0001$. 
melanocytes. Taken together, the cytokine environment suggests a greater immunosuppressive ability in presence of antigen specific Tregs, stimulated by activated effector $\mathrm{T}$ cells. To measure whether this cytokine environment might translate to greater protection of melanocyte target cells from cell death in vitro, we next measured sustained target cell viability in these cocultures of melanocytes, Teff and Tregs.

\section{Antigen Specificity Increases the Immunosuppressive Activity of Tregs In Vitro}

Tregs suppress conventional T cells via cytokines, by cell-to-cell contact or through bystander effects (50). To measure the resulting suppressive activity, we evaluated sustained melanocyte viability in co-cultures of targets, Teffs, and Tregs in vitro for 36 h. Figure 4A shows the viability of targeted HLA-A2 ${ }^{+}$human melanocytes in different combinations of targets, Teffs and Tregs 1:10:1. The number of viable targets increased slightly over time in absence of Teff cells. In comparison, $82.2 \%$ cytotoxicity ( $p<0.0001$ ) was observed in presence of effector T cells after $36 \mathrm{~h}$. Untransduced Tregs offered $35.8 \%(p=0.02)$ protection from cytotoxicity over time. A two-way ANOVA was performed with aligned rank transformation using R-software, and pairwise post-hoc multiple comparison testing according to Tukey to determine that in presence of CAR Tregs, cytotoxicity towards melanocytes was $62.0 \%$ prevented $(\mathrm{p}=0.0004)$. Images representing each combination of cells including targets alone (Figure 4B), targets and Teff (Figure 4C), and the latter combination in presence of untransduced Tregs (Figure 4D) or CAR Tregs (Figure 4E) at different time points likewise reveal most inhibition of cytotoxicity in a combination that includes GD3 CAR Tregs. Thus, both untransduced Tregs and GD3 CAR Tregs offered significant protection of melanocyte viability. Importantly, the protection offered by GD3 CAR Tregs was significantly greater compared to untransduced Tregs ( $p=0.04$ ), demonstrating the added benefit of antigen specificity to enhance immunosuppression. Thus, we next explored the therapeutic effects of CAR Tregs in vivo.

\section{Antigen-Specific Tregs Enhance Immunosuppression in h3TA2 Mice}

To evaluate the suppressive activity of CAR Treg in a model of progressive depigmentation, we measured depigmentation in spontaneously depigmenting h3TA2 mice starting from 5 weeks of age. Depigmentation starts shortly after birth and the animals display half-maximum depigmentation within 23 weeks (51). Mice received adoptively transferred untransduced Tregs, transduced GD3 CAR Tregs or vehicle once every two weeks for 11 weeks as outlined in Figure 5A. Representative dorsal and ventral images of animals transfused with untransduced Tregs, GD3 CAR Tregs, or vehicle are shown in Figure 5B. The Wilcoxon rank sum (WRS) test was used to compare the timeadjusted area under the curve (AUC) among groups. Outcomes for both vehicle and untransduced Treg control groups did not differ (dorsal $p=0.97$, ventral $p=0.88$ ). Therefore, the vehicle and untransduced Treg groups were merged, and compared to the GD3 CAR Treg-treated group. In a one-sided t-approximation for

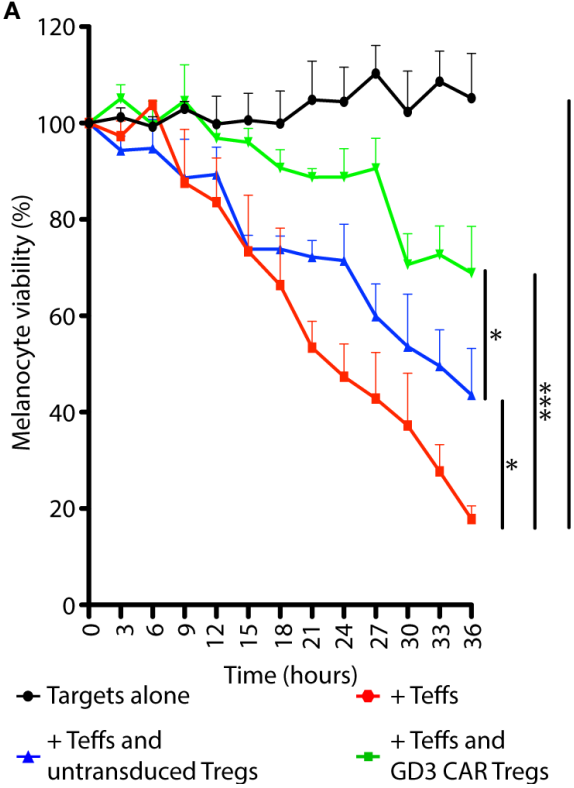

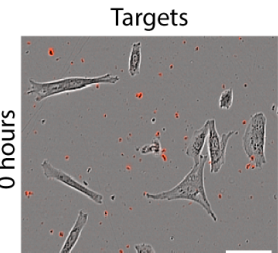
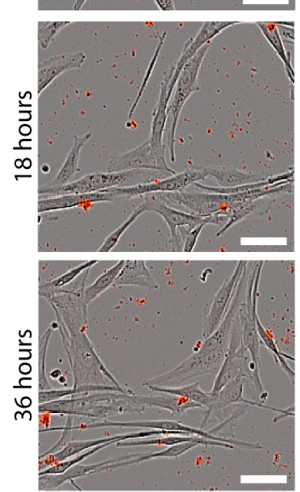<smiles>C1CCCCC1</smiles>
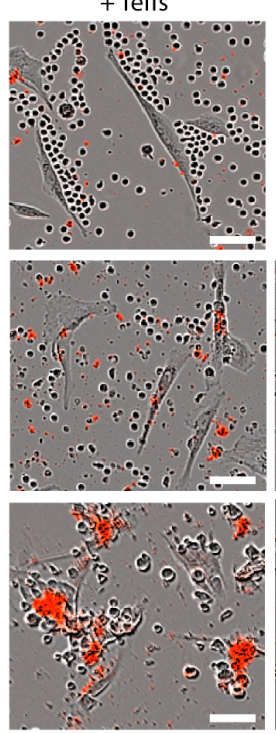

D untransduced Tregs
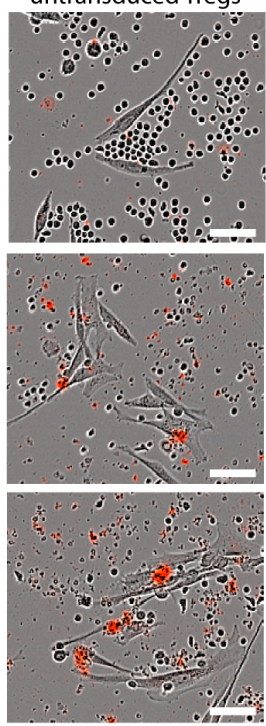

E + Teffs and GD3 CARTregs

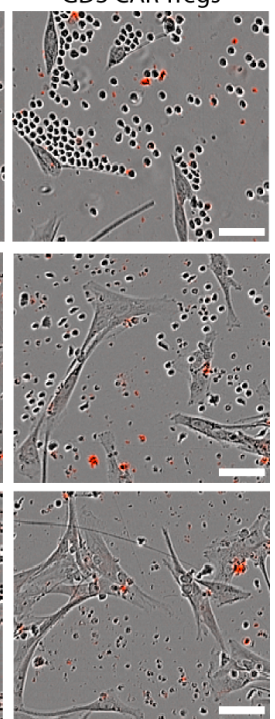

FIGURE 4 | GD3 CAR Tregs provide melanocytes with superior protection from T cell-mediated cytotoxicity in vitro. The immunosuppressive ability of GD3 CAR Tregs and untransduced Tregs was compared in vitro. (A) Viability of HLA-A2 $2^{+}$human melanocytes (targets) in the presence or absence of murine Teffs and Tregs (1:10:1) is represented over time. Representative images of (B) HLA-A2 ${ }^{+}$human melanocytes (C) combined with murine Teffs, and additionally with (D) murine untransduced Tregs, or (E) GD3 CAR Tregs. Dead cells are marked by a red precipitate formed by caspase activity. Statistical significance was determined by two-way ANOVA with aligned rank transformation followed by Tukey's pairwise multiple comparisons test. ${ }^{\star} \mathrm{p}<0.05 ;{ }^{\star \star} \mathrm{p}<0.01 ;{ }^{\star \star \star} \mathrm{p}<0.001 ;{ }^{\star \star \star \star} \mathrm{p}<0.0001$ (Scale bar $=50 \mu \mathrm{m}$ ). 
A Retro-orbital injections

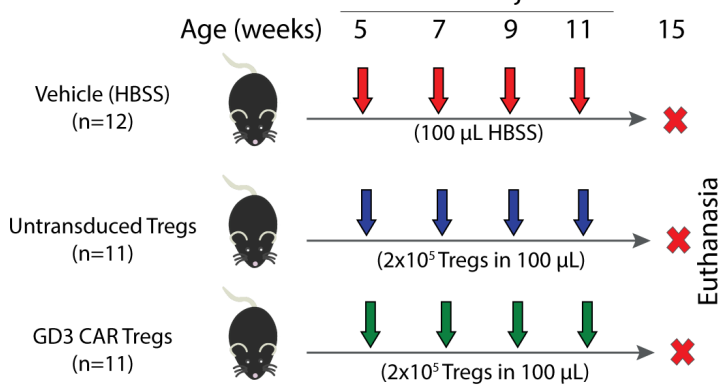

B
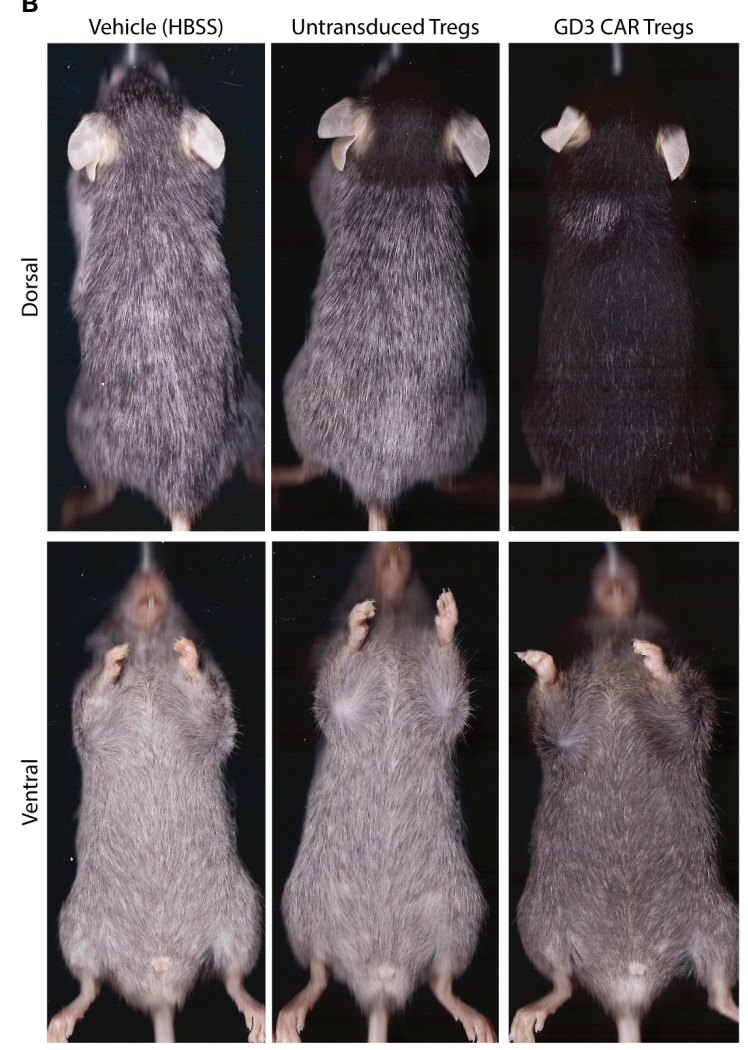

C

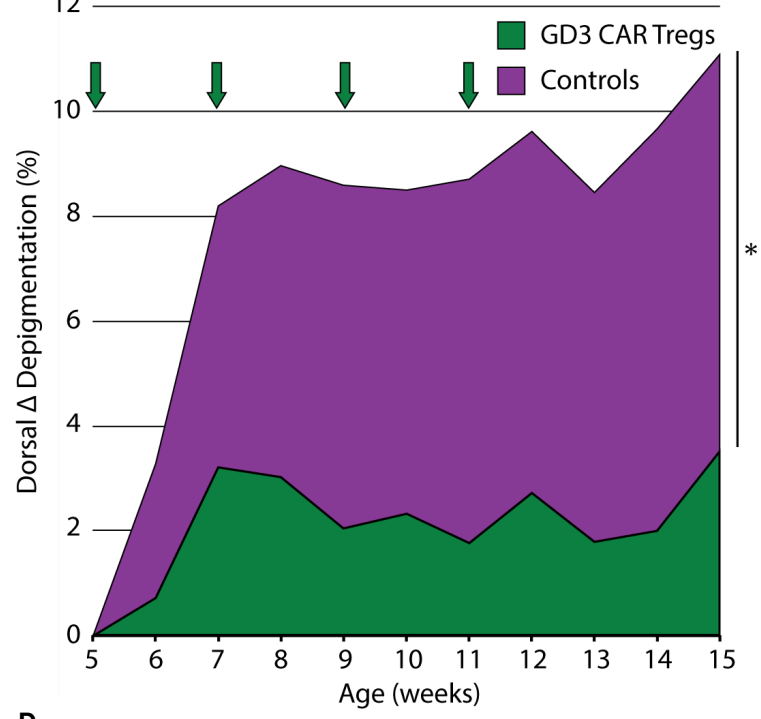

25

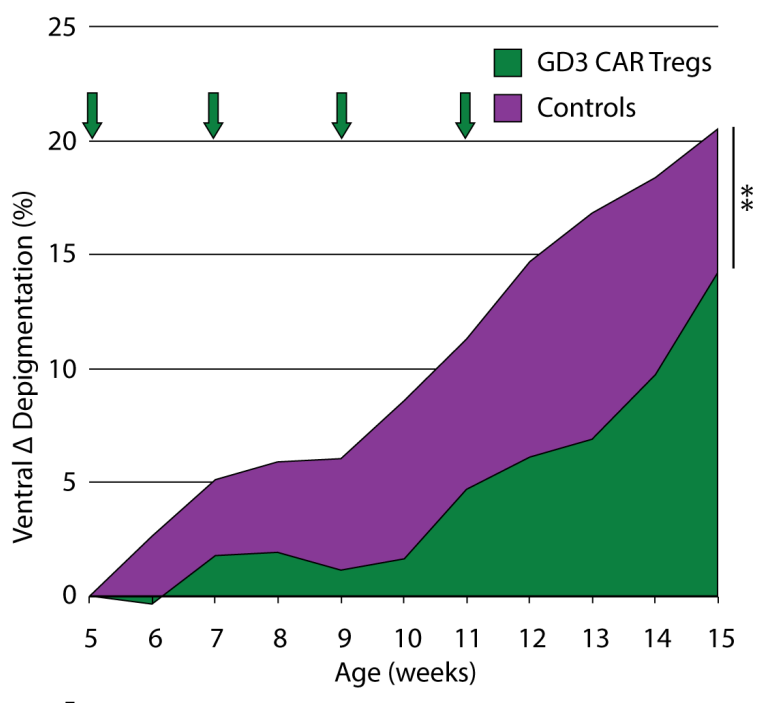

$-5$

FIGURE 5 | GD3 CAR Tregs provide significant protection from depigmentation in vitiligo-prone mice. (A) Experimental outline initiated at 6 different time points showing vitiligo prone, h3TA2, mice treated with vehicle alone $(n=12)$, or by adoptive transfer of untransduced Tregs $(n=11)$ or GD3 CAR Tregs $(n=11)$. Adoptive transfer started at 5 weeks of age and continued biweekly until 11 weeks of age. Depigmentation was measured weekly from 5-15 weeks of age. (B) Representative dorsal and ventral scans of mice from the HBSS vehicle, untransduced Treg, and GD3 CAR Treg treated groups at 15 weeks of age. (C) Depigmentation quantified on dorsal and (D) ventral sides throughout the experiment. The Wilcoxon rank sum (WRS) test was used to compare the time-adjusted AUC among groups. Arrows: treatment times. ${ }^{*} p<0.05 ;{ }^{*} p<0.01$.

the WRS test, the AUC for dorsal depigmentation dropped by $73.0 \%(\mathrm{p}=0.028)$ for CAR Treg treated mice $(\mathrm{n}=11)$ for the $15-$ week observation period. Ventral depigmentation occurs more rapidly and was evaluated separately. Here, depigmentation was significantly delayed among the CAR Treg treated group $(\mathrm{n}=11)$ over the follow-up period (Figure 5C) resulting in a $60.5 \%$ reduction in the AUC ( $\mathrm{p}=0.006)$ among CAR Treg treated mice (Figure 5D). Individual dorsal and ventral depigmentation values for each mouse are shown in the supplementary data file (Supplementary Figure 1). The enhanced disease control by CAR
Tregs might be due to local activation of suppressive activity by GD3 expression and the presence of activated Teff on site. To assess this, changes in serum cytokine content for IFN- $\gamma$, TNF- $\alpha$, IL-4, and IL-10 were measured in serum samples from mice treated with vehicle alone $(\mathrm{n}=11)$, untransduced Tregs $(\mathrm{n}=$ 10), or GD3 CAR Tregs $(n=9)$. Resulting cytokine levels were remarkably consistent among the groups at end point (Supplementary Figure 2). The results support the concept that Tregs, including CAR Tregs, may be preferentially activated on site in areas of immune activity. Adverse events were not observed 

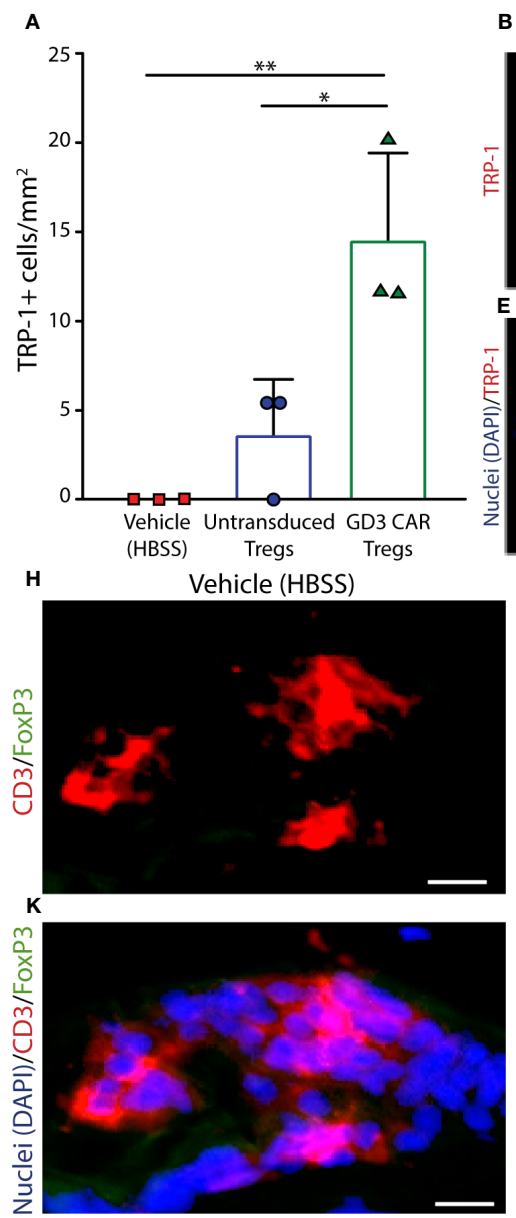

N

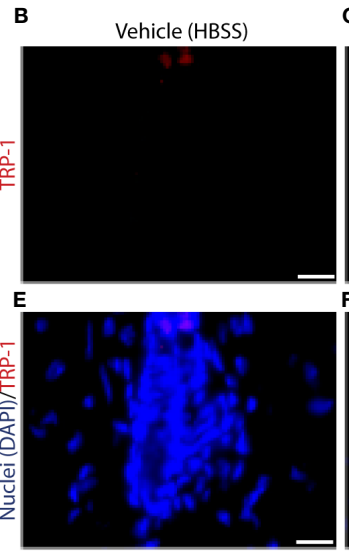

I
C
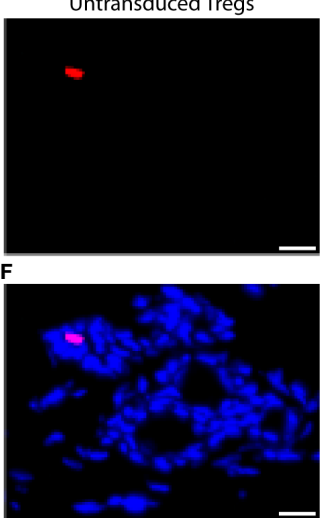

$\mathbf{J}$
D

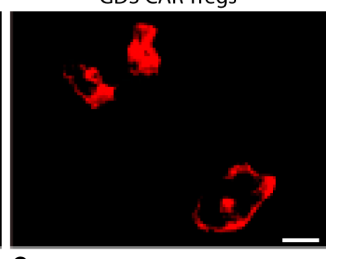

G

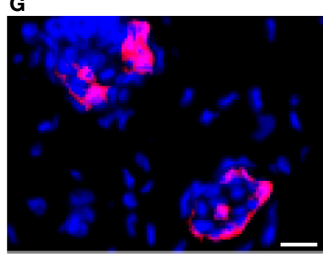

GD3 CAR Tregs

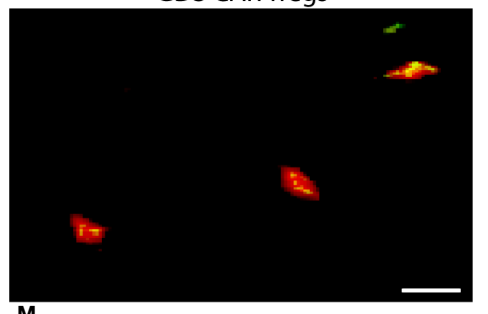

M

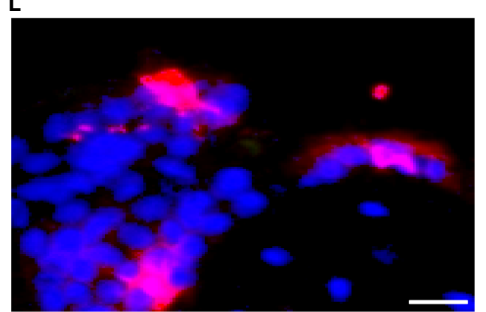

0

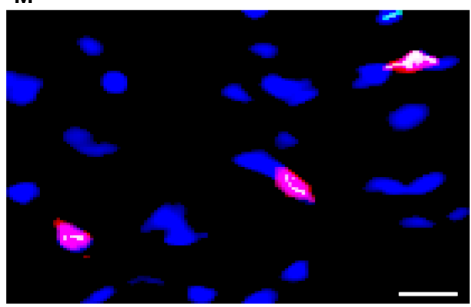

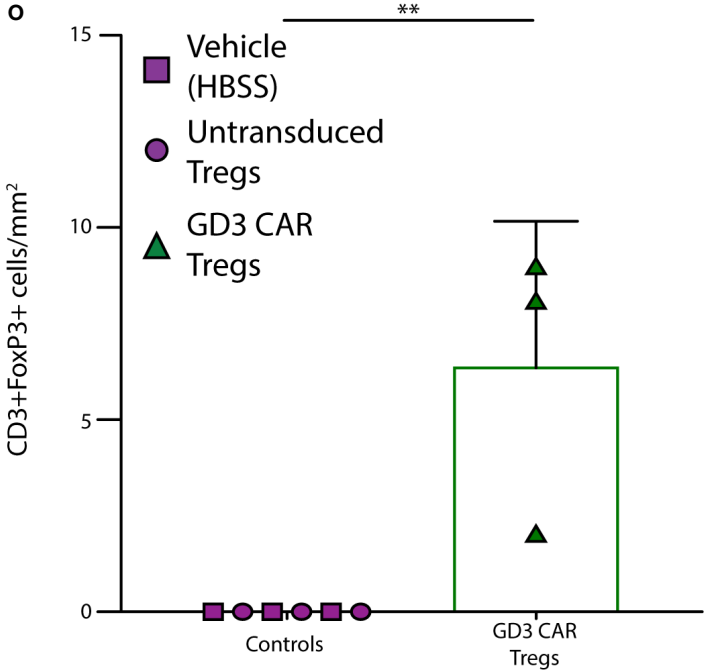

FIGURE 6 | Melanocytes are protected from h3T cytotoxic T cells in the presence of GD3 reactive CAR Tregs. Mouse skin was evaluated for melanocyte presence using antibodies to TRP-1. (A) Quantification of melanocytes, as well as accompanying representative images of TRP-1 staining from (B) HBSS vehicle,

(C) untransduced Tregs, and (D) GD3 CAR Tregs treated mice ( $\mathrm{n}=3$ per group), with (E-G) the respective overlay including DAPI nuclear staining in blue is shown. Mouse skin tissues were also evaluated for T cell infiltration using antibodies to CD3€ and FoxP3, and examples of staining in skin from (H) vehicle control,

(I) untransduced Tregs, and (J) GD3 CAR Tregs administered mice are shown. Representative samples were used to quantify CD3 $\epsilon^{+} \mathrm{T}$ cells (red), FoxP3 cells (green), and double positive Tregs; (K-M) respective overlays with DAPI (blue) are also shown. Quantification of skin staining \pm SD ( $n=3$ per group) for (N) T cells and (0) Tregs are shown, respectively. Statistical analysis was performed by non-parametric t tests. ${ }^{\star} p<0.05,{ }^{\star \star} p<0.001($ Scale bar $=20 \mu m)$. 
throughout the experiment, and no abnormalities were found during internal organ examination at euthanasia for mice from any groups. We next probed whether reduced depigmentation was accompanied by a sustained presence of melanocytes and changes in $\mathrm{T}$ cell populations.

\section{Melanocytes Are Protected in the Presence of GD3 Reactive CAR Tregs}

Mouse dorsal skin biopsies were evaluated for melanocyte abundance using antibodies to TRP-1, as shown in Figure 6. Melanocytes were quantified as shown in Figure 6A, where skin samples from vehicle treated mice ( $n=3$ per group) showed complete loss of melanocytes. Skin from untransduced Treg treated mice ( $\mathrm{n}=3$ per group) displayed only a few remaining melanocytes, and a one-way ANOVA was performed followed by Tukey's post-hoc test to demonstrate that whereas skin from CAR Treg treated mice contained a significantly greater number of melanocytes compared to mice treated with untransduced Tregs $(p=0.025)$, and to vehicle treated controls $(\mathrm{p}=0.006)$. Representative images of TRP-1 staining for vehicle-treated, untransduced Treg-treated, and CAR Treg-treated mice are shown in Figures 6B-D, and overlaid with DAPI nuclear staining in Figures 6E-G, respectively. Similar results were found when examining GD3 expression. Quantification of GD3 expressing cells revealed that mice transfused with CARTregs maintained significantly more GD3 expressing cells than the vehicle HBSS-treated mice $(\mathrm{p}=0.003)$ or mice transfused with untransduced Treg ( $p=0.003$ ) (Supplementary Figure 3). This observation supports the concept that GD3 expressing cells did not experience the cytotoxicity observed in vehicle-treated or untransduced Treg treated mice. This confirmatory melanocyte quantification mainly corresponds with in vivo data shown in Figure 6, demonstrating the improved suppressive ability of CAR Tregs. To explain the differences in pigmentation and melanocyte maintenance, we next compared these data to Treg infiltration in each treatment group.

\section{CAR Tregs Gravitate Towards GD3 Expressing Cells in the Skin}

To understand whether Treg activity is correlated to the abundance of immunosuppressive $\mathrm{T}$ cells on site, mouse skin tissues were evaluated for $\mathrm{T}$ cell infiltration using antibodies to CD3 $€$ and FoxP3. Examples of skin from the vehicle control group, and samples from the mice treated with untransduced or CAR Treg-treated mice are also shown in Figure 6. Tregs were identified as $\mathrm{CD} 3 \epsilon^{+} \mathrm{FoxP}^{+}$cells for the same groups in Figures $\mathbf{6 H}-\mathbf{J}$, respectively, overlaid with DAPI nuclear staining in Figures $6 \mathbf{K}-$ M. CD $3 \epsilon^{+}$cell and $\mathrm{CD} 3 \epsilon^{+} / \mathrm{FoxP}^{+}$Treg abundance was quantified as the mean $\pm \mathrm{SD}$ (at $\mathrm{n}=3$ per group) for each treatment group. In a one-way ANOVA followed by Tukey's post-hoc test, the average number of infiltrating $\mathrm{CD} 3 \epsilon^{+} \mathrm{T}$ cells at end point was 2.3-fold greater $(p=0.02)$ in the control groups as compared to the CAR Treg treated group (Figure $\mathbf{6 N}$ ). No (remaining) $\mathrm{CD}^{+} \mathrm{FoxP}^{+}$ Tregs were detected in either control group, whereas some $\mathrm{CD} 3 \epsilon^{+}$ FoxP3 $^{+}$Tregs were still detectable in skin tissue from CAR Treg treated mice 10 weeks after adoptive transfer (Figure 60). Evaluating Treg numbers by GITR-expression, an increase in Treg numbers at end point was again observed in skin from

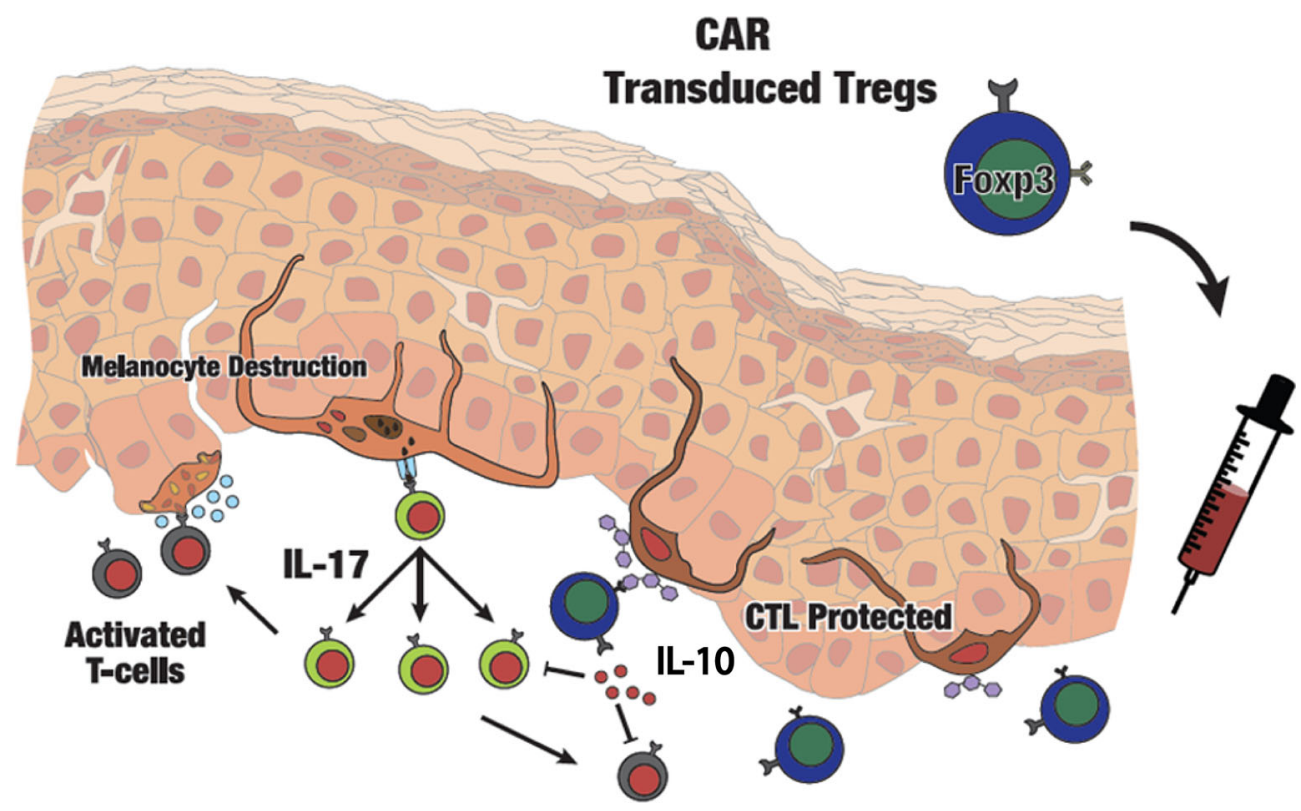

FIGURE 7 | Schematic presentation of adoptive transfer of CAR Tregs in vitiligo. Autoimmune melanocyte destruction is mediated by cytotoxic T cells, which are activated via self-antigens secreted by stressed melanocytes. Elevated IL-17 promotes an inflammatory environment in the skin. Infused GD3-specific CAR Tregs will infiltrate the skin and respond to GD3 expressed at the site of autoimmune activity, suppressing cytotoxic T cells on site and providing local immune tolerance in vitiligo perilesional skin. 
CAR Treg treated mice compared to those treated with untransduced Tregs $(p=0.0059)$ or vehicle alone $(p=0.0089)$, yet there was no difference in abundance of proliferating $\mathrm{GITR}^{+} \mathrm{Ki}^{+}$cells among groups. This suggest that differences in Treg abundance may instead be defined by increased influx or decreased efflux of Tregs from the skin in CAR Treg treated mice (Supplementary Figure 4). Nevertheless, the increased abundance of Tregs in CAR Treg treated mice at end point may explain the improved suppressive activity by CAR Tregs and suggests that maintenance of a Treg presence on site is supported by local antigen recognition (Figure 7). In summary, the data show that antigen specificity prolonged the suppressive activity of adoptively transferred Tregs.

\section{DISCUSSION}

Here we describe the therapeutic potential of engineered GD3 CAR Tregs to provide antigen-specific immune tolerance for autoimmune vitiligo. In contrast to conventional immunosuppressive drugs, biologics, alkylating agents, and antimetabolites, Tregs can provide greater specificity with complex therapeutic benefits, and restore immune tolerance in various autoimmune diseases (20). Preclinical studies have provided promising results when using polyclonal $\mathrm{CD} 4{ }^{+} \mathrm{CD} 25^{+} \mathrm{FoxP}^{+}$Tregs to enforce immune tolerance in various mouse models, including vitiligo (21). A robust human Treg isolation protocol was established to sort Tregs with $>90 \%$ purity, and an ex vivo expansion protocol was developed to acquire upwards of $3 \times 10^{9}$ Tregs from a single donor, similar to the protocol used here (52). Overall, this and other phase I clinical studies provided answers to the isolation, and expansion that surrounded Treg immunotherapy (53-56). Yet the efficacy of polyclonal Treg transfer is not self-evident to date.

In vitiligo, some studies reported no significant differences in circulating Treg numbers $(18,57)$, whereas others report a difference in Treg abundance between vitiligo patient and healthy blood $(15,58)$. Whereas circulating Treg numbers may vary, more consistency is found among reports of a local deficiency of Tregs in patient skin, which might be a cause for uncontrolled peripheral immune responses and progressive depigmentation in vitiligo $(12,18,57)$.

Adoptive transfer of islet-specific Tregs outperformed polyclonal Tregs for blocking type 1 diabetes progression compared to polyclonal Tregs $(20,59,60)$. Unfortunately, diabetes is generally detected in patients when pancreas destruction is near complete, and other conditions may be more amenable to Treg based treatment in a clinical setting. Preclinical studies likewise suggest a superior efficacy of antigenspecific Tregs in transplantation procedures (61-64).

In the h3TA2 mouse model of vitiligo, new Teff are continuously attacking melanocytes, thus reflecting continuously active disease. In these mice, Tregs might be effective for the duration of treatment whereas depigmentation will return when adoptive transfer is halted. Indeed, adoptive Treg treatment is expected to be most efficacious during active disease. In human patients however, progressive disease periods are interspersed with periods of inactivity, providing melanocyte stem cells with an opportunity to differentiate and repopulate the depigmented lesions. Repigmentation can occur in patients treated with JAK inhibitors to suppress Teff activity, though supportive treatment by UV light may be required (65). For intermittent treatment of vitiligo, it will be beneficial to store autologous GD3 CAR Tregs for later use (66).

By virtue of their antigen specificity, these Tregs might provide better safety profiles and decrease the risk of generalized immunosuppression. This is supported by increased IL-10 secretion found where Tregs function in presence of activated Teff, as shown here. When comparing Tregs expressing first and second generation CARs, cells expressing a second-generation CAR with a $28 \zeta$ costimulatory domain the greatest amount of IL-10 (67). The CAR Treg construct used to transduce the Tregs included in our paper similarly showed significant IL-10 production upon activation through the CAR, which might explain the improved suppressive activity of these GD3 CAR Tregs compared to untransduced Tregs in vitro. Indeed, TCR and CAR transduction may also produce more potent and stable Tregs for in vivo, clinical use in vitiligo, and this condition holds an important advantage for investigating the superiority of antigen-specific Tregs by offering several target antigens associated with the condition (68). TNF- $\alpha$ was significantly elevated both in culture and in serum of experimental mice. Nevertheless, genetic ablation of TNF- $\alpha$ was not correlated with the development of vitiligo, and no difference in depigmentation was found when compared to wild type h3TA2 mice (21). In vitiligo, TNF- $\alpha$ plays a role in the development cytotoxic $\mathrm{T}$ cells (CTLs) and enhances expression of IFN- $\gamma$, which are implicated in imitation of vitiligo development $(21,69,70)$. Recent studies reports that TNF- $\alpha$ might promote anti-inflammatory conditions via activation and induction of Treg proliferation in vivo (71-73). Thus, TNF- $\alpha$ can potentially be both destructive and protective in vitiligo, by promoting CTLs and stimulating Tregs, respectively. While TNF- $\alpha$ depletion halted the disease progression and promoted repigmentation in vitiligo, 18 of 5,928 patients developed vitiligo de novo when TNF- $\alpha$ inhibitors were administered for other autoimmune disorders. This leaves anti-TNF- $\alpha$ treatment option for vitiligo until side effects are fully averted (74).

We thus asked whether antigen-specific $\mathrm{T}$ regs might provide additional benefit for the treatment of the autoimmune disease vitiligo. This condition holds a complex etiology (2), with melanocyte loss as a common denominator and immune mechanisms held universally responsible for the spread of disease. TCR- and CAR-based Tregs possess different mechanistic and functional properties. Low-antigen expression levels are sufficient for TCR-based Tregs to become activated, whereas CAR-based Tregs require high density of antigens (75, 76) suggesting that TCRs or CARs could be selected based on antigen expression by target tissue. We performed repeat Treg injections, because the mice in our model exhibit chronically active disease and we do not yet know how long transgenic Tregs remain active on site. The long-term fate of adoptively 
transferred Treg has yet to be established to better understand the need for repeated applications. Importantly, CARs are not subjected to HLA restriction and hold a higher affinity for their targets moieties (77). Thus, a CAR construct can find a universal application for patients with progressive disease.

We identified a potential target for antigen-specific Tregs in vitiligo. Our GD3 CAR Tregs protect melanocytes from T cellmediated destruction in a mouse model of vitiligo, expressing a human TCR and matched human MHC, and capable of responding to human target cells. Importantly, the antigen of choice does not need to be expressed by target cells spared in the response themselves (78).

Though no side effects were apparent in our current studies during internal organ examination, some safety concerns remain, including the possible development of cytokine release syndrome (CRS) or neurotoxicity if transduced cells ultimately develop an effector profile (79). CRS is however more likely to develop when targeting liquid tumors than in solid tissues (80). To counter any potential side effects and promote safety, a construct that includes a caspase-based suicide gene can be incorporated in order to inactivate the GD3 CAR Tregs if necessary $(81,82)$.

A limitation to intravenous injection of antigen specific Tregs might be that these much-needed immunosuppressive cells display a paucity at the desired site (60). Should systemically applied Tregs not respond as required, local injection might be needed, or the CCR4 Treg homing receptor ligand CCL22, can be introduced where Tregs are needed to attract systemically applied Tregs (17). This leaves autoimmune diseases of the skin especially suited for adoptive treatment by antigen-specific Tregs when relevant antigens can be identified. In fact, GD3 might support keratinocyte proliferation while $\mathrm{O}$-acetylated GD3 was overexpressed in psoriatic skin $(83,84)$. These findings suggest that GD3 CAR Tregs might temper lesions in the latter condition as well.

To date, only alloantigen-reactive Tregs are currently being tested to prevent rejection after organ transplantation in clinical trials (60). Here we prepared and expanded GD3 reactive CAR Tregs in amounts suited for adoptive cell transfer therapy in mice. The same can be pursued in patients, cryopreserving the therapeutic Tregs for future use (85-88). One of the challenges of adoptive transfer is the cost and scalability of the technique. This has prompted the concept of developing off-the-shelf "Universal CAR Tregs" readily adaptable for all patients. Versatility is provided by modules that bind both the universal CAR and the target cell (89). In summary, the data provided here support the use of antigenspecific CAR Tregs as an adoptive cell therapy for vitiligo, to control depigmentation and support immune tolerance in vitiligo.

Treg infusion has thus far been well tolerated in patients. The results from currently ongoing clinical trials can bring important insights regarding the optimal Treg dose, expected efficacy and any concern that may arise about possible side effects, and the treatment strategy can be further adjusted to support continued maintenance and memory formation (90), improved homing (91), and safety measures to eliminate adoptively transferred cells (92) as needed. The efficacy and specificity of Treg therapy for conditions other than vitiligo can be enhanced where antigens can be identified to serve as targets for engineered, antigenspecific Tregs. In vivo tracking will allow research groups to better understand the maintenance and memory-forming potential of antigen-specific Tregs. In conclusion, Treg-based therapy holds potential as a future therapy for vitiligo and for other autoimmune skin diseases.

\section{DATA AVAILABILITY STATEMENT}

The original contributions presented in the study are included in the article/Supplementary Material. Further inquiries can be directed to the corresponding authors.

\section{ETHICS STATEMENT}

The animal study was reviewed and approved by Northwestern University's Institutional Animal Care and Use Committee. Written informed consent was obtained from the individual(s) for the publication of any potentially identifiable images or data included in this article.

\section{AUTHOR CONTRIBUTIONS}

Conceptualization: CLP and ZM. Methodology: ZM, CLP, CC, and DJ. Formal Analysis, ZM. Investigation, ZM, ERD, JME, and KP-M. Statistical analysis, AI and KC. Resources, RPJ, SM and AO. Writing-Original Draft, ZM. Writing-Review and Editing, ZM, CLP, ERD, YOO and JRL. Visualization, ZM, ERD, JME and SWH. Supervision, CLP. Project Administration, CLP. All authors contributed to the article and approved the submitted version.

\section{FUNDING}

This study was supported in part by NIH RO1s AR057643, CA191317, and by The LAM Foundation through an Established Investigator award to CLP. A foreign internship to ZM was supported by the Ministry of Education and Science of the Republic of Kazakhstan under the Ph.D. program at Al-Farabi Kazakh National University.

\section{ACKNOWLEDGMENTS}

We kindly acknowledge NCI Biological Resources Branch for providing rhIL-2 used for in vivo studies. We greatly appreciate the patients who provide informed consent to use the skin tissues for the study, and Northwestern University Skin Biology and Diseases Resource-Based Center (SBDRC) TEST IT core for the technical assistance.

\section{SUPPLEMENTARY MATERIAL}

The Supplementary Material for this article can be found online at: https://www.frontiersin.org/articles/10.3389/fimmu.2020. 581433/full\#supplementary-material 


\section{REFERENCES}

1. Ezzedine K, Eleftheriadou V, Whitton M, van Geel N. Vitiligo. Lancet (London England) (2015) 386(9988):74-84. doi: 10.1016/s0140-6736(14) 60763-7

2. Kundu RV, Mhlaba JM, Rangel SM, Le Poole IC. The convergence theory for vitiligo: A reappraisal. Exp Dermatol (2019) 28(6):647-55. doi: 10.1111/ exd.13677

3. Henning SW, Jaishankar D, Barse LW, Dellacecca ER, Lancki N, Webb K, et al. The relationship between stress and vitiligo: Evaluating perceived stress and electronic medical record data. PloS One (2020) 15(1):e0227909. doi: 10.1371/journal.pone.0227909

4. Grimes PE, Miller MM. Vitiligo: Patient stories, self-esteem, and the psychological burden of disease. Int J women's Dermatol (2018) 4(1):32-7. doi: 10.1016/j.ijwd.2017.11.005

5. Osinubi O, Grainge MJ, Hong L, Ahmed A, Batchelor JM, Grindlay D, et al. The prevalence of psychological comorbidity in people with vitiligo: a systematic review and meta-analysis. Br J Dermatol (2018) 178(4):863-78. doi: 10.1111/bjd.16049

6. Frisoli ML, Essien K, Harris JE. Vitiligo: Mechanisms of Pathogenesis and Treatment. Annu Rev Immunol (2020) 38:621-48. doi: 10.1146/annurevimmunol-100919-023531

7. Mosenson JA, Flood K, Klarquist J, Eby JM, Koshoffer A, Boissy RE, et al. Preferential secretion of inducible HSP70 by vitiligo melanocytes under stress. Pigm Cell melanoma Res (2014) 27(2):209-20. doi: 10.1111/pcmr.12208

8. Tulic MK, Cavazza E, Cheli Y, Jacquel A, Luci C, Cardot-Leccia N, et al. Innate lymphocyte-induced CXCR3B-mediated melanocyte apoptosis is a potential initiator of T-cell autoreactivity in vitiligo. Nat Commun (2019) 10 (1):2178. doi: 10.1038/s41467-019-09963-8

9. Jacquemin C, Rambert J, Guillet S, Thiolat D, Boukhedouni N, Doutre MS, et al. Heat shock protein 70 potentiates interferon alpha production by plasmacytoid dendritic cells: relevance for cutaneous lupus and vitiligo pathogenesis. Br J Dermatol (2017) 177(5):1367-75. doi: 10.1111/bjd.15550

10. Le Poole IC, Wankowicz-Kalinska A, van den Wijngaard RM, Nickoloff BJ, Das PK. Autoimmune aspects of depigmentation in vitiligo. J Invest Dermatol Symp Proc (2004) 9(1):68-72. doi: 10.1111/j.1087-0024.2004.00825.x

11. Bhardwaj S, Rani S, Kumaran MS, Bhatia A, Parsad D. Expression of Th17and Treg-specific transcription factors in vitiligo patients. Int J Dermatol (2020) 59(4):474-81. doi: 10.1111/ijd.14766

12. Le Poole IC, Mehrotra S. Replenishing Regulatory T Cells to Halt Depigmentation in Vitiligo. J Invest Dermatol Symp Proc (2017) 18(2):S38s45. doi: 10.1016/j.jisp.2016.10.023

13. Levings MK, Sangregorio R, Roncarolo MG. Human $c d 25(+) c d 4(+) t$ regulatory cells suppress naive and memory $\mathrm{T}$ cell proliferation and can be expanded in vitro without loss of function. J Exp Med (2001) 193(11):1295302. doi: $10.1084 /$ jem.193.11.1295

14. Zhang $\mathrm{X}$, Olsen $\mathrm{N}$, Zheng SG. The progress and prospect of regulatory $\mathrm{T}$ cells in autoimmune diseases. J Autoimmun (2020) 111:102461. doi: 10.1016/ j.jaut.2020.102461

15. Dwivedi M, Laddha NC, Arora P, Marfatia YS, Begum R. Decreased regulatory T-cells and $\mathrm{CD} 4(+) / \mathrm{CD} 8(+)$ ratio correlate with disease onset and progression in patients with generalized vitiligo. Pigm Cell Melanoma Res (2013) 26(4):586-91. doi: 10.1111/pcmr.12105

16. Giri PS, Dwivedi M, Laddha NC, Begum R, Bharti AH. Altered expression of nuclear factor of activated T cells, forkhead box P3, and immune-suppressive genes in regulatory T cells of generalized vitiligo patients. Pigm Cell melanoma Res (2020) 33(4):566-78. doi: 10.1111/pcmr.12862

17. Eby JM, Kang HK, Tully ST, Bindeman WE, Peiffer DS, Chatterjee S, et al. CCL22 to Activate Treg Migration and Suppress Depigmentation in Vitiligo. J Invest Dermatol (2015) 135(6):1574-80. doi: 10.1038/jid.2015.26

18. Klarquist J, Denman CJ, Hernandez C, Wainwright DA, Strickland FM, Overbeck A, et al. Reduced skin homing by functional Treg in vitiligo. Pigm Cell melanoma Res (2010) 23(2):276-86. doi: 10.1111/j.1755148X.2010.00688.X

19. Hegab DS, Attia MA. Decreased Circulating T Regulatory Cells in Egyptian Patients with Nonsegmental Vitiligo: Correlation with Disease Activity. Dermatol Res Pract (2015) 2015:145409. doi: 10.1155/2015/145409
20. Ferreira LMR, Muller YD, Bluestone JA, Tang Q. Next-generation regulatory T cell therapy. Nat Rev Drug Discovery (2019) 18(10):749-69. doi: 10.1038/ s41573-019-0041-4

21. Chatterjee S, Eby JM, Al-Khami AA, Soloshchenko M, Kang HK, Kaur N, et al. A quantitative increase in regulatory $\mathrm{T}$ cells controls development of vitiligo. J Invest Dermatol (2014) 134(5):1285-94. doi: 10.1038/jid.2013.540

22. Serra P, Santamaria P. Nanoparticle-based autoimmune disease therapy. Clin Immunol (Orlando Fla) (2015) 160(1):3-13. doi: 10.1016/j.clim.2015.02.003

23. Mathew JM, Voss JH, McEwen ST, Konieczna I, Chakraborty A, Huang X, et al. Generation and Characterization of Alloantigen-Specific Regulatory T Cells For Clinical Transplant Tolerance. Sci Rep (2018) 8(1):1136. doi: 10.1038/s41598-018-19621-6

24. Dawson NAJ, Levings MK. Antigen-specific regulatory T cells: are police CARs the answer? Trans Res J Lab Clin Med (2017) 187:53-8. doi: 10.1016/ j.trsl.2017.06.009

25. Oren R, Hod-Marco M, Haus-Cohen M, Thomas S, Blat D, Duvshani N, et al. Functional comparison of engineered $\mathrm{T}$ cells carrying a native TCR versus TCRlike antibody-based chimeric antigen receptors indicates affinity/avidity thresholds. J Immunol (2014) 193(11):5733-43. doi: 10.4049/jimmunol.1301769

26. Abbott RC, Cross RS, Jenkins MR. Finding the Keys to the CAR: Identifying Novel Target Antigens for T Cell Redirection Immunotherapies. Int J Mol Sci (2020) 21(2):515. doi: 10.3390/ijms21020515

27. Brusko TM, Koya RC, Zhu S, Lee MR, Putnam AL, McClymont SA, et al. Human antigen-specific regulatory $\mathrm{T}$ cells generated by $\mathrm{T}$ cell receptor gene transfer. PloS One (2010) 5(7):e11726. doi: 10.1371/journal.pone.0011726

28. Jin Y, Ferrara T, Gowan K, Holcomb C, Rastrou M, Erlich HA, et al. Nextgeneration DNA re-sequencing identifies common variants of TYR and HLAA that modulate the risk of generalized vitiligo via antigen presentation. J Invest Dermatol (2012) 132(6):1730-3. doi: 10.1038/jid.2012.37

29. Mehrotra S, Al-Khami AA, Klarquist J, Husain S, Naga O, Eby JM, et al. A coreceptor-independent transgenic human TCR mediates anti-tumor and anti-self immunity in mice. J Immunol (Baltimore Md 1950) (2012) 189 (4):1627-38. doi: 10.4049/jimmunol.1103271

30. Mosenson JA, Zloza A, Nieland JD, Garrett-Mayer E, Eby JM, Huelsmann EJ, et al. Mutant HSP70 reverses autoimmune depigmentation in vitiligo. Sci Trans Med (2013) 5(174):174ra28. doi: 10.1126/scitranslmed.3005127

31. Le Poole IC, Stennett LS, Bonish BK, Dee L, Robinson JK, Hernandez C, et al. Expansion of vitiligo lesions is associated with reduced epidermal CDw60 expression and increased expression of HLA-DR in perilesional skin. $\mathrm{Br} \mathrm{J}$ Dermatol (2003) 149(4):739-48. doi: 10.1046/j.1365-2133.2003.05539.x

32. Kemminer SE, Conradt HS, Nimtz M, Sagi D, Peter-Katalinić J, Diekmann O, et al. Production and molecular characterization of clinical phase i antimelanoma mouse IgG3 monoclonal antibody R24. Biotechnol Prog (2001) 17 (5):809-21. doi: 10.1021/bp010068y

33. Kniep B, Flegel WA, Northoff H, Rieber EP. CDw60 glycolipid antigens of human leukocytes: structural characterization and cellular distribution. Blood (1993) 82(6):1776-86. doi: 10.1182/blood.V82.6.1776.1776

34. Nakano J, Yasui H, Lloyd KO, Muto M. Biologic roles of gangliosides G(M3) and G(D3) in the attachment of human melanoma cells to extracellular matrix proteins. J Invest Dermatol Symp Proc (1999) 4(2):173-6. doi: 10.1038/ sj.jidsp.5640204

35. Birklé S, Gao L, Zeng G, Yu RK. Down-regulation of GD3 ganglioside and its $\mathrm{O}$-acetylated derivative by stable transfection with antisense vector against GD3-synthase gene expression in hamster melanoma cells: effects on cellular growth, melanogenesis, and dendricity. J Neurochem (2000) 74(2):547-54. doi: $10.1046 / j .1471-4159.2000 .740547 . x$

36. Karagaiah P, Valle Y, Sigova J, Zerbinati N, Vojvodic P, Parsad D, et al. Emerging drugs for the treatment of vitiligo. Expert Opin emerging Drugs (2020) 25(1):7-24. doi: 10.1080/14728214.2020.1712358

37. Henning SW, Fernandez MF, Mahon JP, Duff R, Azarafrooz F, GuevaraPatino JA, et al. HSP70iQ435A-Encoding DNA Repigments Vitiligo Lesions in Sinclair Swine. J Invest Dermatol (2018) 138(12):2531-9. doi: 10.1016/ j.jid.2018.06.186

38. Wu X, Ragupathi G, Panageas K, Hong F, Livingston PO. Accelerated tumor growth mediated by sublytic levels of antibody-induced complement activation is associated with activation of the PI3K/AKT survival pathway. Clin Cancer Res (2013) 19(17):4728-39. doi: 10.1158/1078-0432.ccr-13-0088 
39. Abnaof K, Mallela N, Walenda G, Meurer SK, Seré K, Lin Q, et al. TGF- $\beta$ stimulation in human and murine cells reveals commonly affected biological processes and pathways at transcription level. BMC Syst Biol (2014) 8(1):55. doi: 10.1186/1752-0509-8-55

40. Tsang ML, Zhou L, Zheng BL, Wenker J, Fransen G, Humphrey J, et al. Characterization of recombinant soluble human transforming growth factorbeta receptor type II (rhTGF-beta sRII). Cytokine (1995) 7(5):389-97. doi: 10.1006/cyto.1995.0054

41. Arkin MR, Randal M, DeLano WL, Hyde J, Luong TN, Oslob JD, et al. Binding of small molecules to an adaptive protein-protein interface. Proc Natl Acad Sci (2003) 100(4):1603. doi: 10.1073/pnas.252756299

42. Arenas-Ramirez N, Woytschak J, Boyman O. Interleukin-2: Biology, Design and Application. Trends Immunol (2015) 36(12):763-77. doi: 10.1016/ j.it.2015.10.003

43. Lo AS, Ma Q, Liu DL, Junghans RP. Anti-GD3 chimeric sFv-CD28/T-cell receptor zeta designer $\mathrm{T}$ cells for treatment of metastatic melanoma and other neuroectodermal tumors. Clin Cancer Res an Off J Am Assoc Cancer Res (2010) 16(10):2769-80. doi: 10.1158/1078-0432.Ccr-10-0043

44. Yun CO, Nolan KF, Beecham EJ, Reisfeld RA, Junghans RP. Targeting of T lymphocytes to melanoma cells through chimeric anti-GD3 immunoglobulin T-cell receptors. Neoplasia (New York NY) (2000) 2(5):449-59. doi: 10.1038/ sj.neo.7900108

45. Furlan SN, Singh K, Lopez C, Tkachev V, Hunt DJ, Hibbard J, et al. IL-2 enhances ex vivo-expanded regulatory T-cell persistence after adoptive transfer. Blood Adv (2020) 4(8):1594-605. doi: 10.1182/bloodadvances.2019001248

46. Wang J, Zhang S-X, Hao Y-F, Qiu M-T, Luo J, Li Y-Y, et al. The numbers of peripheral regulatory $\mathrm{T}$ cells are reduced in patients with psoriatic arthritis and are restored by low-dose interleukin-2. Ther Adv chronic Dis (2020) 11:2040622320916014-. doi: 10.1177/2040622320916014

47. Denman CJ, McCracken J, Hariharan V, Klarquist J, Oyarbide-Valencia K, Guevara-Patiño JA, et al. HSP70i Accelerates Depigmentation in a Mouse Model of Autoimmune Vitiligo. J Invest Dermatol (2008) 128(8):2041-8. doi: 10.1038/jid.2008.45

48. Faria AR, Tarlé RG, Dellatorre G, Mira MT. Castro CCSd. Vitiligo - Part 2 classification, histopathology and treatment. Anais Brasileiros Dermatol (2014) 89:784-90. doi: 10.1590/abd1806-4841.20142717

49. Wagner RY, Luciani F, Cario-André M, Rubod A, Petit V, Benzekri L, et al. Altered E-Cadherin Levels and Distribution in Melanocytes Precede Clinical Manifestations of Vitiligo. J Invest Dermatol (2015) 135(7):1810-9. doi: $10.1038 /$ jid.2015.25

50. Schmidt A, Oberle N, Krammer PH. Molecular mechanisms of treg-mediated T cell suppression. Front Immunol (2012) 3:51:51. doi: 10.3389/fimmu.2012.00051

51. Eby JM, Kang HK, Klarquist J, Chatterjee S, Mosenson JA, Nishimura MI, et al. Immune responses in a mouse model of vitiligo with spontaneous epidermal de- and repigmentation. Pigm Cell melanoma Res (2014) 27 (6):1075-85. doi: 10.1111/pcmr.12284

52. Putnam AL, Brusko TM, Lee MR, Liu W, Szot GL, Ghosh T, et al. Expansion of human regulatory T-cells from patients with type 1 diabetes. Diabetes (2009) 58(3):652-62. doi: 10.2337/db08-1168

53. Bluestone JA, Buckner JH, Fitch M, Gitelman SE, Gupta S, Hellerstein MK, et al. Type 1 diabetes immunotherapy using polyclonal regulatory T cells. Sci Transl Med (2015) 7(315):315ra189. doi: 10.1126/scitranslmed.aad4134

54. Marek-Trzonkowska N, Mysliwiec M, Dobyszuk A, Grabowska M, Techmanska I, Juscinska J, et al. Administration of CD4+CD25highCD127regulatory $\mathrm{T}$ cells preserves $\beta$-cell function in type 1 diabetes in children. Diabetes Care (2012) 35(9):1817-20. doi: 10.2337/dc12-0038

55. Marek-Trzonkowska N, Myśliwec M, Siebert J, Trzonkowski P. Clinical application of regulatory T cells in type 1 diabetes. Pediatr Diabetes (2013) 14(5):322-32. doi: 10.1111/pedi.12029

56. Marek-Trzonkowska N, Mysliwiec M, Dobyszuk A, Grabowska M, Derkowska I, Juscinska J, et al. Therapy of type 1 diabetes with CD4(+) CD25(high)CD127-regulatory T cells prolongs survival of pancreatic islets results of one year follow-up. Clin Immunol (2014) 153(1):23-30. doi: 10.1016/j.clim.2014.03.016

57. Ben Ahmed M, Zaraa I, Rekik R, Elbeldi-Ferchiou A, Kourda N, Belhadj Hmida N, et al. Functional defects of peripheral regulatory $\mathrm{T}$ lymphocytes in patients with progressive vitiligo. Pigm Cell Melanoma Res (2012) 25(1):99109. doi: 10.1111/j.1755-148X.2011.00920.x
58. Lili Y, Yi W, Ji Y, Yue S, Weimin S, Ming L. Global activation of CD8+ cytotoxic $\mathrm{T}$ lymphocytes correlates with an impairment in regulatory $\mathrm{T}$ cells in patients with generalized vitiligo. PloS One (2012) 7(5):e37513. doi: 10.1371/ journal.pone. 0037513

59. Raffin C, Vo LT, Bluestone JA. T(reg) cell-based therapies: challenges and perspectives. Nat Rev Immunol (2020) 20(3):158-72. doi: 10.1038/s41577019-0232-6

60. Bluestone JA, Tang Q. T(reg) cells-the next frontier of cell therapy. Science (2018) 362(6411):154-5. doi: 10.1126/science.aau2688

61. Trenado A, Charlotte F, Fisson S, Yagello M, Klatzmann D, Salomon BL, et al. Recipient-type specific CD4+CD25+ regulatory $\mathrm{T}$ cells favor immune reconstitution and control graft-versus-host disease while maintaining graftversus-leukemia. J Clin Invest (2003) 112(11):1688-96. doi: 10.1172/jci17702

62. Golshayan D, Jiang S, Tsang J, Garin MI, Mottet C, Lechler RI. In vitroexpanded donor alloantigen-specific $\mathrm{CD} 4+\mathrm{CD} 25+$ regulatory $\mathrm{T}$ cells promote experimental transplantation tolerance. Blood (2007) 109(2):827-35. doi: 10.1182/blood-2006-05-025460

63. Sagoo P, Ali N, Garg G, Nestle FO, Lechler RI, Lombardi G. Human regulatory $\mathrm{T}$ cells with alloantigen specificity are more potent inhibitors of alloimmune skin graft damage than polyclonal regulatory T cells. Sci Transl Med (2011) 3(83):83ra42. doi: 10.1126/scitranslmed.3002076

64. Noyan F, Lee YS, Hardtke-Wolenski M, Knoefel AK, Taubert R, Baron U, et al. Donor-specific regulatory $\mathrm{T}$ cells generated on donor $\mathrm{B}$ cells are superior to $\mathrm{CD} 4+\mathrm{CD} 25$ high cells in controlling alloimmune responses in humanized mice. Transplant Proc (2013) 45(5):1832-7. doi: 10.1016/j.transproceed. 2013.01.073

65. Liu LY, Strassner JP, Refat MA, Harris JE, King BA. Repigmentation in vitiligo using the Janus kinase inhibitor tofacitinib may require concomitant light exposure. J Am Acad Dermatol (2017) 77(4):675-82.e1. doi: 10.1016/ j.jaad.2017.05.043

66. MacDonald KN, Ivison S, Hippen KL, Hoeppli RE, Hall M, Zheng G, et al. Cryopreservation timing is a critical process parameter in a thymic regulatory T-cell therapy manufacturing protocol. Cytotherapy (2019) 21(12):1216-33. doi: 10.1016/j.jcyt.2019.10.011

67. Boroughs AC, Larson RC, Choi BD, Bouffard AA, Riley LS, Schiferle E, et al. Chimeric antigen receptor costimulation domains modulate human regulatory T cell function. JCI Insight (2019) 4(8):e126194. doi: 10.1172/ jci.insight. 126194

68. Le Poole IC, Luiten RM. Autoimmune etiology of generalized vitiligo. Curr Dir Autoimmun (2008) 10:227-43. doi: 10.1159/000131485

69. Ranges GE, Figari IS, Espevik T, Palladino MAJr. Inhibition of cytotoxic T cell development by transforming growth factor beta and reversal by recombinant tumor necrosis factor alpha. J Exp Med (1987) 166(4):991-8. doi: 10.1084/ jem.166.4.991

70. Scheurich P, Thoma B, Ucer U, Pfizenmaier K. Immunoregulatory activity of recombinant human tumor necrosis factor (TNF)-alpha: induction of TNF receptors on human $\mathrm{T}$ cells and TNF-alpha-mediated enhancement of T cell responses. J Immunol (1987) 138(6):1786-90.

71. Grinberg-Bleyer Y, Saadoun D, Baeyens A, Billiard F, Goldstein JD, Grégoire $S$, et al. Pathogenic T cells have a paradoxical protective effect in murine autoimmune diabetes by boosting Tregs. J Clin Invest (2010) 120(12):4558-68. doi: $10.1172 /$ jci 42945

72. Biton J, Semerano L, Delavallée L, Lemeiter D, Laborie M, Grouard-Vogel G, et al. Interplay between TNF and regulatory T cells in a TNF-driven murine model of arthritis. J Immunol (2011) 186(7):3899-910. doi: 10.4049/ jimmunol.1003372

73. Biton J, Boissier MC, Bessis N. TNFo: activator or inhibitor of regulatory T cells? Joint Bone Spine (2012) 79(2):119-23. doi: 10.1016/j.jbspin.2011. 09.017

74. Webb KC, Tung R, Winterfield LS, Gottlieb AB, Eby JM, Henning SW, et al. Tumour necrosis factor- $\alpha$ inhibition can stabilize disease in progressive vitiligo. Br J Dermatol (2015) 173(3):641-50. doi: 10.1111/bjd.14016

75. Watanabe K, Terakura S, Martens AC, van Meerten T, Uchiyama S, Imai M, et al. Target antigen density governs the efficacy of anti-CD20-CD28-CD3 $\zeta$ chimeric antigen receptor-modified effector CD8+ T cells. J Immunol (2015) 194(3):911-20. doi: 10.4049/jimmunol.1402346

76. Walker AJ, Majzner RG, Zhang L, Wanhainen K, Long AH, Nguyen SM, et al. Tumor Antigen and Receptor Densities Regulate Efficacy of a Chimeric 
Antigen Receptor Targeting Anaplastic Lymphoma Kinase. Mol Ther (2017) 25(9):2189-201. doi: 10.1016/j.ymthe.2017.06.008

77. Chmielewski M, Hombach AA, Abken H. Of CARs and TRUCKs: Chimeric antigen receptor (CAR) T cells engineered with an inducible cytokine to modulate the tumor stroma. Immunol Rev (2014) 257(1):83-90. doi: 10.1111/imr.12125

78. Raffin C, Zhou Y, Piccoli L, Lanzavecchia A, Sadelain M, Bluestone JA. Development of citrullinated-vimentin-specific CAR for targeting Tregs to treat autoimmune rheumatoid arthritis. J Immunol (2018) 200:176.

79. Hua J, Inomata T, Chen Y, Foulsham W, Stevenson W, Shiang T, et al. Pathological conversion of regulatory $\mathrm{T}$ cells is associated with loss of allotolerance. Sci Rep (2018) 8(1):7059. doi: 10.1038/s41598-018-25384-x

80. Junghans RP. The challenges of solid tumor for designer CAR-T therapies: a 25-year perspective. Cancer Gene Ther (2017) 24(3):89-99. doi: 10.1038/ cgt.2016.82

81. Jones BS, Lamb LS, Goldman F, Di Stasi A. Improving the safety of cell therapy products by suicide gene transfer. Front Pharmacol (2014) 5:254:254. doi: 10.3389/fphar.2014.00254

82. Rossignoli F, Grisendi G, Spano C, Golinelli G, Recchia A, Rovesti G, et al. Inducible Caspase9-mediated suicide gene for MSC-based cancer gene therapy. Cancer Gene Ther (2019) 26(1-2):11-6. doi: 10.1038/s41417-018-0034-1

83. Paller AS, Arnsmeier SL, Alvarez-Franco M, Bremer EG. Ganglioside GM3 inhibits the proliferation of cultured keratinocytes. J Invest Dermatol (1993) 100(6):841-5. doi: 10.1111/1523-1747.ep12476755

84. Huang BB, Bonish BK, Chaturvedi V, Qin JZ, Nickoloff BJ. Keratinocyte CDw60 expression is modulated by both a Th-1 type cytokine IFN-gamma and Th-2 cytokines IL-4 and IL-13: relevance to psoriasis. J Invest Dermatol (2001) 116(2):305-12. doi: 10.1046/j.1523-1747.2001.01242.x

85. Safinia N, Vaikunthanathan T, Fraser H, Thirkell S, Lowe K, Blackmore L, et al. Successful expansion of functional and stable regulatory $\mathrm{T}$ cells for immunotherapy in liver transplantation. Oncotarget (2016) 7(7):7563-77. doi: 10.18632 /oncotarget.6927

86. Hippen KL, Merkel SC, Schirm DK, Sieben CM, Sumstad D, Kadidlo DM, et al. Massive ex vivo expansion of human natural regulatory $\mathrm{T}$ cells ( $\mathrm{T}(\mathrm{regs})$ ) with minimal loss of in vivo functional activity. Sci Transl Med (2011) 3 (83):83ra41. doi: 10.1126/scitranslmed.3001809

87. Weiner J, Duran-Struuck R, Zitsman J, Buhler L, Sondermeijer H, McMurchy AN, et al. Restimulation After Cryopreservation and Thawing Preserves the
Phenotype and Function of Expanded Baboon Regulatory T Cells. Transplant Direct (2015) 1(1):1-7. doi: 10.1097/txd.0000000000000511

88. Guo H, Zhang H, Lu L, Ezzelarab MB, Thomson AW. Generation, cryopreservation, function and in vivo persistence of ex vivo expanded cynomolgus monkey regulatory T cells. Cell Immunol (2015) 295(1):19-28. doi: 10.1016/j.cellimm.2015.02.006

89. Koristka S, Kegler A, Bergmann R, Arndt C, Feldmann A, Albert S, et al. Engrafting human regulatory $\mathrm{T}$ cells with a flexible modular chimeric antigen receptor technology. J Autoimmun (2018) 90:116-31. doi: 10.1016/ j.jaut.2018.02.006

90. Rost F, Lambert K, Rakebrandt N, Joller N. Preceding Viral Infections Do Not Imprint Long-Term Changes in Regulatory T Cell Function. Sci Rep (2020) 10 (1):8350. doi: 10.1038/s41598-020-65212-9

91. Bonacina F, Martini E, Svecla M, Nour J, Cremonesi M, Beretta G, et al. Adoptive transfer of CX3CR1 transduced-T regulatory cells improves homing to the atherosclerotic plaques and dampens atherosclerosis progression. Cardiovasc Res (2020). doi: 10.1093/cvr/cvaa264

92. Boursier G, Siri A, de Boysson H. [Use of regulatory $\mathrm{T}$ cells in cellular therapies in autoimmune diseases]. Med Sci M/S (2012) 28(8-9):757-63. doi: $10.1051 /$ medsci/2012288018

Conflict of Interest: United States and PCT international patent (Utility\&PCT, serial No.17/072,939\&PCT/US2020/056104) filed as "Materials and methods for treating vitiligo" on 10/16/2020.

The authors declare that the research was conducted in the absence of any commercial or financial relationships that could be construed as a potential conflict of interest.

Copyright (c) 2020 Mukhatayev, Dellacecca, Cosgrove, Shivde, Jaishankar, PontaroloMaag, Eby, Henning, Ostapchuk, Cedercreutz, Issanov, Mehrotra, Overbeck, Junghans, Leventhal and Le Poole. This is an open-access article distributed under the terms of the Creative Commons Attribution License (CC BY). The use, distribution or reproduction in other forums is permitted, provided the original author(s) and the copyright owner(s) are credited and that the original publication in this journal is cited, in accordance with accepted academic practice. No use, distribution or reproduction is permitted which does not comply with these terms. 